\title{
Possible Side Reactions Due to Water in Emulsion Polymerization by Late Transition Metal Complexes. 1. Water Complexation and Hydrolysis of the Growing Chain
}

\author{
Iordan H. Hristov, ${ }^{\dagger}$ Roger L. DeKock, ${ }^{\ddagger}$ Grant D. W. Anderson, ${ }^{\dagger}$ Inigo Göttker-Schnetmann, ${ }^{\S}$ \\ Stefan Mecking, ${ }^{\S}$ and Tom Ziegler ${ }^{*, \dagger}$ \\ Department of Chemistry, University of Calgary, 2500 University Drive NW, Calgary, \\ Alberta, Canada T2N 1N4, Department of Chemistry and Biochemistry, Calvin College, \\ 3201 Burton Street SE, Grand Rapids, Michigan 49546-4388, and Faculty of Science, \\ University of Konstanz, Universitätsstr. 10, D-78464 Konstanz, Germany
}

\begin{abstract}
The transition metal catalyzed ethylene polymerization in aqueous emulsion has been increasingly successful in the last couple of years. Water however adversely affects the polymerization process by (a) competing with ethylene for the binding site at the metal and (b) hydrolyzing the growing chain. Neutral salicylaldiminato and cationic diimine complexes of $\mathrm{Ni}$ and $\mathrm{Pd}$ with different substituent patterns are studied here by density functional theory to determine their propensity toward water complexation and hydrolysis of the growing chain. Experimental NMR studies have also been carried out on the protonolysis of the $\mathrm{Ni}(\mathrm{II})$-based Grubbs catalyst. It is found that in general that (a) ethylene coordination is preferred over water coordination for both $\mathrm{Ni}$ and $\mathrm{Pd}$ catalysts and (b) hydrolysis of the metal alkyl bond is competitive to ethylene insertion.
\end{abstract}

\section{Introduction}

Emulsion polymerization of olefinic monomers is an important and versatile process. ${ }^{1}$ Polymer lattices are obtained, that is, aqueous dispersions of surfactant-stabilized polymer microparticles with a size range of 50-1000 nm. Important applications of lattices involve film formation upon evaporation of the dispersing medium (e.g., in coatings), and here the environmental friendliness and nonflammability of water is particularly advantageous. To date, polymer lattices are produced industrially by free radical processes exclusively. Transition metal catalyzed coordination polymerization has received comparatively little attention, as the early transition metal catalysts ${ }^{2}$ used commercially for polyolefin

* To whom correspondence should be addressed. E-mail: ziegler@ ucalgary.ca.

$\dagger$ University of Calgary.

$\doteqdot$ Calvin College.

$\S$ University of Konstanz.

(1) (a) Lovell, P. A.; El-Aasser, M. S. Emulsion Polymerization and Emulsion Polymers; Wiley: Chichester, 1997. (b) Wäßrige Polymerdispersionen; Distler, D., Ed.; VCH: Weinheim, 1999. (c) Lagaly, G.; Schulz, O.; Zimehl, R. Dispersionen und Emulsionen; Steinkopff: Darmstadt, 1997. (d) Fitch, R. M. Polymer Colloids a Comprehensive Introduction; Academic Press: San Diego, 1997.

(2) Fink, G.; Mülhaupt, R.; Brintzinger, H. H. Ziegler Catalysts; Springer: Berlin, 1995. production are extremely sensitive to moisture. Carrying out such reactions in water is a highly attractive goal, as many polymer microstructures are not available by other means than catalytic coordination polymerization. In view of a possible potential for catalytic coordination polymerization in aqueous emulsion, the reactivity toward water of metal complexes already known to polymerize olefins to higher molecular weight products in nonaqueous systems is of interest.

Considering catalytic transformations in aqueous media in general, complexes of late transition metals are good candidates due to their reduced oxophilicity. This is illustrated by the commercial application of aqueous two-phase catalysis in the Ruhrchemie-Rhone-Poulenc process for propylene hydroformylation. ${ }^{3}$ It has long been assumed that coordination polymerizations in aqueous media are possible in principle. ${ }^{4}$ However, the coordination polymerization of

(3) (a) Ziegler Catalysts; Fink, G., Mülhaupt, R., Brintzinger, H. H, Eds. Springer: Berlin, 1995. (b) Brintzinger, H. H.; Fischer, D.; Mülhaupt, R ; Rieger, B.; Waymouth, R. Angew. Chem. 1995, 107, 1255; Angew. Chem., Int. Ed. Engl. 1995, 34, 1143. (c) Britovsek, G. J. P.; Gibson, V. C.; Wass, D. F. Angew. Chem. 1999, 111, 448; Angew. Chem. Int. Ed. 1999, 38, 428. (d) Kaminsky, W.; Arndt, M. Adv. Polym. Sci. 1997, 127, 143

(4) Reppe, W.; Magin, A. U.S. Patent 2,577,208, 1948. 


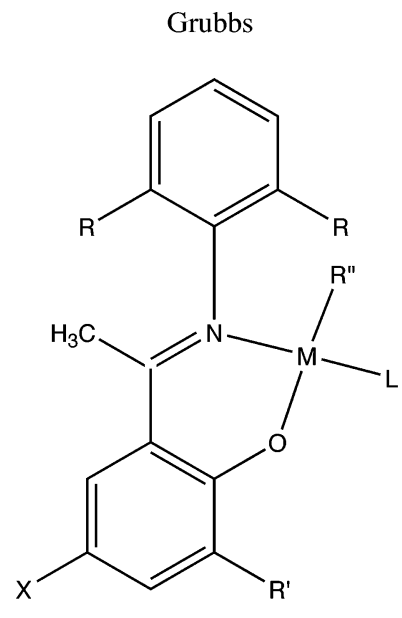

a

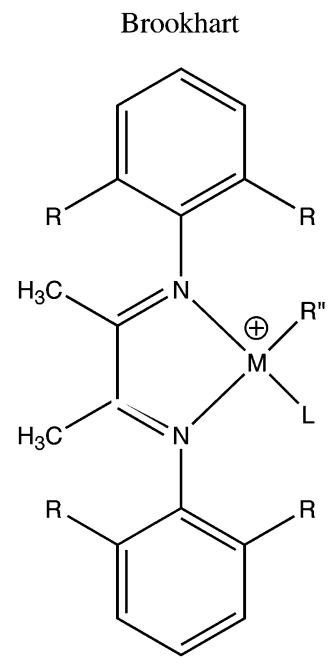

b

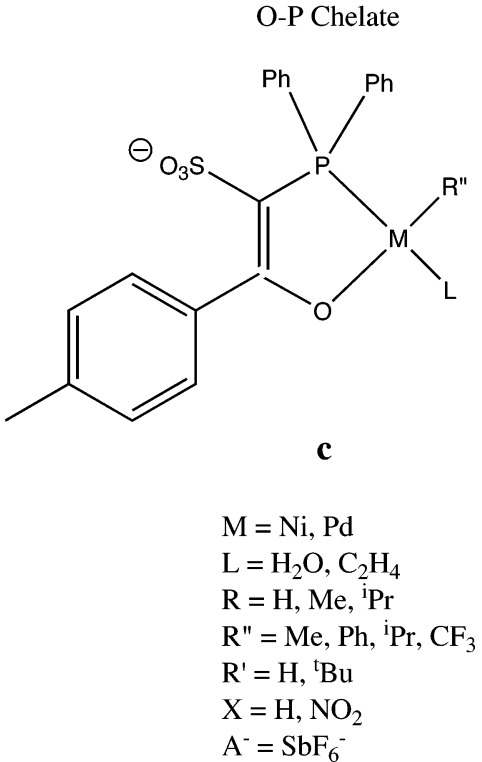

Figure 1. Schematic structures of the catalyst species investigated.

simple olefins in emulsion has only very recently begun to attract interest. $\mathrm{We}^{5}$ and Claverie and Spitz et al. ${ }^{6,7}$ have reported coordination polymerization of ethylene in aqueous emulsion or suspension by neutral nickel(II) salicyladiminato complexes (introduced as polymerization catalysts by Grubbs et al. and Johnson et al. ${ }^{8}$ ), by cationic palladium(II) diimine complexes (introduced as olefin polymerization catalysts by Brookhart et al. ${ }^{9}$ ), as well as the well-known $\mathrm{P} \wedge \mathrm{O}$-chelated neutral nickel(II) complexes, ${ }^{10}$ Figure 1.

The polymerization chemistry of the salicylaldiminato and diimine systems in organic solvents has been extensively studied by theoretical methods. ${ }^{11}$ In this paper we are only going to investigate the catalysts' stability toward water.

(5) (a) Held, A.; Bauers, F. M.; Mecking, S. Chem. Commun. 2000, 301 (b) Held, A.; Mecking, S. Chem.-Eur. J. 2000, 6, 4623. (c) Bauers, F. M.; Mecking, S. Macromolecules 2001, 34, 1165. (d) Bauers, F. M.; Mecking, S. Angew. Chem. 2001, 113, 3112; Angew. Chem., Int. Ed. 2001, 40, 3020. (e) Bauers, F. M.; Chowdhry, M. M.; Mecking, S. Macromolecules 2003, 36, 6711. (f) Bauers, F. M.; Thomann, R.; Mecking, S. J. Am. Chem. Soc. 2003, 125, 8838. (g) Zuideveld, M. A.; Wehrmann, P.; Röhr, C.; Mecking, S. Angew. Chem. 2004, 116, 887; Angew. Chem., Int. Ed. 2004, 43, 869.

(6) (a) Tomov, A.; Broyer, J.-P.; Spitz, R. Macromol. Symp. 2000, 150, 53. (b) Soula, R.; Novat, C ; Tomov, A.; Spitz, R.; Claverie, J.; Drujon, X.; Malinge, J.; Saudemont, T. Macromolecules 2001, 34, 2022. (c) Soula, R.; Saillard, B.; Spitz, R.; Claverie, J.; Llaurro, M. F.; Monnet, C. Macromolecules 2002, 35, 1513 .

(7) For a very slow (1 turnover/day) Rh-catalyzed reaction of ethylene to low-molecular-weight material, cf. Wang, L.; Lu, R. S.; Bau, R.; Flood, T. C. J. Am. Chem. Soc 1993, 115, 6999.

(8) (a) Wang, C.; Friedrich, S.; Younkin, T. R.; Li, R. T.; Grubbs, R. H.; Bansleben, D. A.; Day, M. W. Organometallics 1998, 17, 3149. (b) Younkin, T. R.; Connor, E. F.; Henderson, J. I.; Friedrich, S. K.; Grubbs, R. H.; Bansleben, D. A. Science 2000, 287, 460. (c) Connor, E. F.; Younkin, T. R.; Henderson, J. I.;Waltman, A. W.; Grubbs, R. H. Chem. Commun. 2003, 2272. (d) Johnson, L. K.; Bennett, A. M. A.; Ittel, S. D.; Wang, L.; Parthasarathy, A.; Hauptman, E.; Simpson, R. D.; Feldman, J.; Coughlin, E. B. (DuPont) WO98/30609, 1998.

(9) Johnson, L. K.; Killian, C. M.; Brookhart, M. J. Am. Chem. Soc. 1995, $117,6414$.

(10) (a) Keim, W.; Kowaldt, F. H.; Goddard, R.; Krueger, C. Angew. Chem., Int. Ed. Engl. 1978, 17, 466; Angew. Chem. 1978, 90, 493. (b) Klabunde, U.; Ittel, S. D. J. Mol. Catal. 1987, 41, 123. (c) OstojaStarzewski, K. A.; Witte, J. Angew. Chem. 1987, 99, 76; Angew. Chem., Int. Ed. Engl. 1987, 26, 63.
In preliminary experimental investigations, low-temperature NMR studies revealed that the water ligand in the palladium diimine complex $\left(\mathrm{R}={ }^{\mathrm{i}} \mathrm{Pr}, \mathrm{L}=\mathrm{H}_{2} \mathrm{O}\right.$, see Figure 1) is displaced completely upon addition of ethylene. ${ }^{5 a}$ Since the binding of water in the first coordination sphere can be the initial step toward the hydrolysis of the growing chain, we have looked at the relative complexation energies of water vs ethylene for all three catalyst systems shown in Figure 1 as a function of the substituent groups. The results are presented in the first part of our discussion.

Hydrolysis of the $\mathrm{M}-\mathrm{R}^{\prime \prime}$ bond (see Figure 1) to release a hydrocarbon $\mathrm{H}-\mathrm{R}^{\prime \prime}$ and form a $\mathrm{M}-\mathrm{OH}$ hydroxy link is another possible side reaction. This is a similar process to the reverse of the $\mathrm{C}-\mathrm{H}$ activation process that has been observed for some palladium(II) complexes. ${ }^{12}$ This type of hydrolysis process is considered in part two of our discussion for all three catalyst types shown in Figure 1. To date experiments seem to indicate that catalysts of the Brookhart type are stable in aqueous solution at room temperature for days. ${ }^{5 b}$

Experiment ${ }^{5 b}$ has shown that the addition of ethylene to the Pd(II)-based Brookhart catalyst in aqueous solution leads to immediate decomposition to palladium black; the reason for this decomposition has not been clarified. Thus, only a suspension-type ethylene polymerization has been reported,

(11) (a) Woo, T. K.; Margl, P. M.; Deng, L.; Cavallo, L.; Ziegler, T. Catal. Today 1999, 50, 479 (b) Michalak, A.; Ziegler, T. Organometallics 2003, 22, 2069. (c) Deng, L.; Woo, T. K.; Cavallo, L.; Margl, P. M.; Ziegler, T. J. Am. Chem. Soc. 1997, 119, 6177. (d) Michalak, A.; Ziegler, T. Organometallics 2001, 20, 1521. (e) Deubel, D.; Ziegler, T. Organometallics 2002, 21, 1603. (f) Milano, G.; Guerra, G.; Pellecchia, C.; Cavallo, L. Organometallics 2000, 19, 1343. (g) Svensson, M.; Matsubara, T.; Morokuma, K. Organometallics 1996, 15, 5568. (h) Chan, M. S. W.; Deng, L.; Ziegler, T. Organometallics 2000, 19, 2741.

(12) (a) Biswas, B.; Sugimoto, M.; Sakaki, S. Organometallics 2000, 19 3895. (b) Fang, X.; Scott, B. L.; Watkin, J. G.; Kubas, G. J. Organometallics 2000, 19, 4193. (c) Tempel, D. J.; Johnson, L. K.; Huff, R. L.; White, P. S.; Brookhart, M. J. Am. Chem. Soc. 2000, 122,6686 . 
Scheme 1. QM/MM Partition of the Molecule Structures

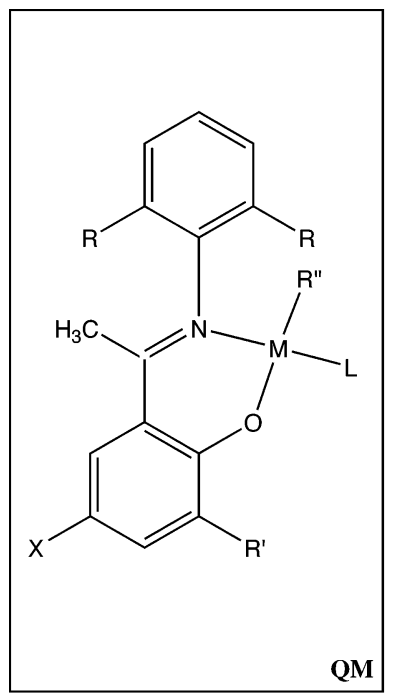

QM
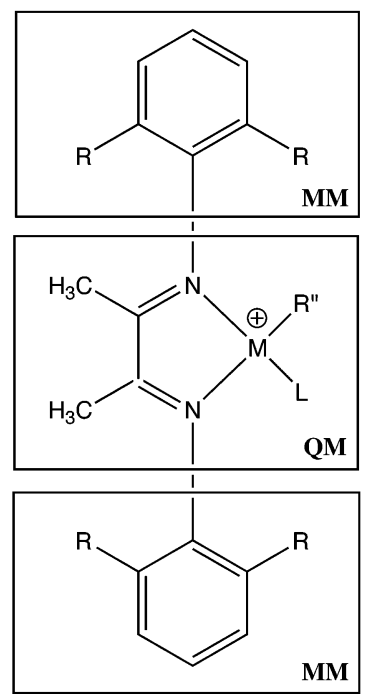

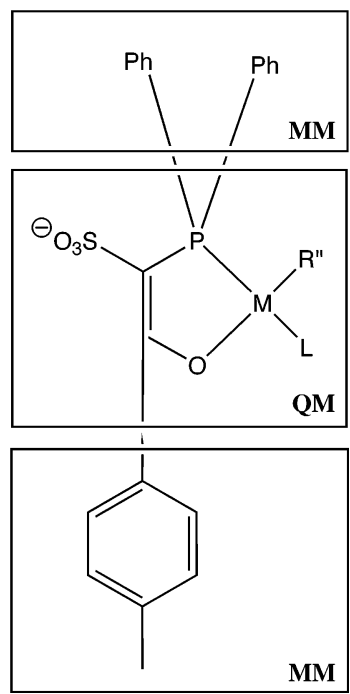

in which the catalyst is protected from the access of water in the initial stages of the reaction by being employed as a water-insoluble solid of relatively large particle size, and latterly by being encapsulated in the hydrophobic amorphous polyethylene formed. Although no organic products were isolated in the catalyst decomposition process, it is possible that the decomposition occurs by a Wacker-type reaction. ${ }^{13}$ A theoretical discussion of this deactivation will be presented in a forthcoming paper of possible side reactions that might lead to catalyst decomposition in aqueous solution. ${ }^{14}$

\section{Computational Method}

All calculations were carried out using the Amsterdam Density Functional (ADF 2.3.3) program $^{15}$ developed by Baerends et al. ${ }^{16}$ and vectorized by Ravenek. ${ }^{17}$ The numerical integration scheme applied for the calculations was developed by Velde and coworkers. ${ }^{18}$ The geometry optimization procedure was based on the method of Versluis and Ziegler. ${ }^{19}$ Geometry optimizations were carried out and energy differences determined using the local density approximation of Vosko, Wilk, and Nusair (LDA VWN) ${ }^{20}$ augumented with the nonlocal gradient correction PW91 from Perdew and Wang. ${ }^{21}$ Relativistic corrections were added using a scalarrelativistic Pauli Hamiltonian. ${ }^{22}$ All atoms except Ni were described by a core double- $\zeta$, valence triple- $\zeta$, polarized basis set, and $\mathrm{Ni}$ was described by a core double- $\zeta$, valence triple- $\zeta$, doubly polarized

(13) (a)Siegbahn, P. E. M. J. Am. Chem. Soc. 1995, 117, 5409. (b) Siegbahn, P. E. M. J. Phys. Chem. 1996, 100, 14762.

(14) DeKock, R. L.; Hristov, I. H.; Anderson, G. D. W.; GottkerSchnetmann, I.; Mecking, S.; Ziegler, T. Organometallics 2005, 24, 2679.

(15) Amsterdam Density Functional program, Division of Theoretical Chemistry, Vrije Universiteit, De Boelelaan 1083, 1081 HV Amsterdam, The Netherlands; www.scm.com.

(16) Baerends, E. J.; Ellis, D. E.; Ros, P. Chem. Phys. 1973, 2, 41

(17) Ravenek, W. In Algorithms and Applications on Vector and Parallel Computers; te Riele, H. J. J., Dekker, T. J., van de Horst, H. A., Eds.; Elsevier: Amsterdam, 1987

(18) Boerrigter, P. M.; Velde, G. T.; Baerends, E. J. Int. J. Quantum Chem. 1988, 33, 87

(19) Versluis, L.; Ziegler, T. J. Chem. Phys. 1988, 88, 322.

(20) Vosko, S. H.; Wilk, L.; Nusair, M. Can. J. Phys. 1980, 58, 1200.

(21) Perdew, J. P.; Wang, Y. Phys. Rev. B 1986, 33, 8800.

(22) Snijders, J. G.; Baerends, E. J.; Ros, P. Mol. Phys. 1979, 38, 1909. basis. Non-hydrogen atoms were assigned a relativistic frozen-core potential, treating as core shells up to and including $3 \mathrm{~d}$ for $\mathrm{Pd} ; 2 \mathrm{p}$ for $\mathrm{S}, \mathrm{P}$, and $\mathrm{Ni} ; 1$ s for $\mathrm{C}, \mathrm{N}$, and $\mathrm{O}$. A set of auxiliary s, p, d, f, and $\mathrm{g}$ functions, centered on all nuclei, was used to fit the molecular density and to represent the Coulomb and exchange potentials accurately in each SCF cycle. The counterions have not been included in the model for simplicity. Solvation energies were calculated from gas-phase structures by using the Conductor-like Screening Model (COSMO) ${ }^{23}$ that has been implemented ${ }^{24 a}$ recently into the ADF program. ${ }^{24 \mathrm{~b}}$ The solvation calculations were performed with a dielectric constant of 2.38 for toluene. The radii used for the atoms (in $\AA$ ) are as follows: H 1.16, S 1.7, C 2.3, O 1.3, N 1.4, P 2.4, Ni 1.25, Pd 1.38. Some of these values were obtained previously by optimization using least-squares fitting to experimental solvation energies. ${ }^{25}$ Transition states were fully optimized using the algorithm of Banerjee et al. ${ }^{26}$ starting from the structures obtained by linear transit calculations. The Brookhart and the $\mathrm{O}-\mathrm{P}$ chelate systems were calculated using the QM/MM method. ${ }^{27}$ An augmented AMBER95 force field ${ }^{28}$ was utilized to describe the molecular mechanics potential. The separation of the catalyst molecule into a QM and MM part is illustrated in Scheme 1. For the Grubbs catalyst the complete system was described by QM.

The bond lengths for $\mathrm{C}-\mathrm{N}, \mathrm{C}-\mathrm{C}$, and $\mathrm{C}-\mathrm{P}$ that link the $\mathrm{QM}$ and $\mathrm{MM}$ parts have been calculated for the generic compounds with a full QM calculation. The capping atoms used were hydrogens. Each link bond has a constant parameter $\alpha$ associated with it, ${ }^{29}$ which was 1.41 for the $\mathrm{N}-\mathrm{C}$ bond in the Grubbs systems, 1.29 for the $\mathrm{C}-\mathrm{P}$ bonds, and 1.36 for the $\mathrm{C}-\mathrm{C}$ bond in the $\mathrm{O}-\mathrm{P}$ chelate system.

(23) Klamt, A.; Schuurmann, G. J. Chem. Soc.-Perkin Trans. 2 1993, 5 , 799 .

(24) (a) Pye, C. C.; Ziegler, T. Theor. Chem. Acc. 1999, 101, 396. (b) Velde, G. T.; Bickelhaupt, F. M.; Baerends, E. J.; Guerra, C. F.; Van Gisbergen, S. J. A.; Snijders, J. G.; Ziegler, T. J. Comput. Chem. 2001, 22, 931.

(25) Marcus, Y. J. Chem. Soc.-Faraday Trans. 1991, 87, 2995.

(26) (a) Banerjee, A.; Adams, N.; Simons, J.; Shepard, R. J. Phys. Chem. 1985, 89, 52. (b) Fan, L.; Ziegler, T. J. Chem. Phys. 1990, 92, 3645.

(27) (a) Woo, T. K.; Cavallo, L.; Ziegler, T. Theor. Chem. Acc. 1998, 100 307. (b) Reference 11a.

(28) Cornell, W. D.; Cieplak, P.; Bayly, C. I.; Gould, I. R.; Merz, K. M.; Ferguson, D. M.; Spellmeyer, D. C.; Fox, T ; Caldwell, J. W.; Kollman, P. A. J. Am. Chem. Soc. 1995, 117, 5179.

(29) (a) Reference 27a. (b) Woo, T. K. Ph.D. Thesis, University of Calgary, Canada, 1998. 


\section{Experimental Conditions}

General Considerations for NMR Protonolysis Studies of Ni(II)-Based Grubbs Complexes $G_{\exp } 14 a, b-(L)$ [a: $R=3,5-\left(C_{3}\right)$ $\mathrm{C}_{6} \mathrm{H}_{3}$, b: 3,5-Xylyl; $\mathbf{R}^{\prime}=\mathrm{X}=\mathrm{I}: \mathbf{R}^{\prime \prime}=\mathrm{Me} ; \mathrm{L}=\mathrm{Me}_{2} \mathrm{NCH}_{2} \mathrm{CH}_{2^{-}}$ $\mathrm{NMe}_{2}$ (tmeda), Pyridine, $\left.\mathrm{PPh}_{3}\right]$ as Shown in Scheme 1. All samples were prepared in a nitrogen atmosphere glovebox. Benzene$d_{6}$ was thoroughly degassed by several freeze-pump-thaw cycles and vacuum-transferred from finely dispersed sodium metal prior to use. Methanol- $d_{4}$ and deuterium oxide were degassed. Complexes $\mathrm{G}_{\text {exp }} 14 \mathrm{a}, \mathrm{b}-(\mathrm{L})(\mathrm{L}=$ tmeda, pyridine) were prepared according to known procedures. ${ }^{5 \mathrm{~g}} \mathrm{G}_{\text {exp }} 14 \mathrm{a}, \mathrm{b}-\left(\mathrm{PPh}_{3}\right)$ were prepared in analogy to the pyridine complexes by reacting $\mathrm{G}_{\exp } 14 \mathrm{a}$,b-(tmeda) with $\mathrm{PPh}_{3}$ and removal of excess $\mathrm{PPh}_{3}$. Complexes $\mathrm{G}_{\text {exp }} 14 \mathrm{a}$,b-(tmeda) are dynamic mixtures of several isomers in benzene- $d_{6}$ solution. However, upon addition of $\mathrm{CD}_{3} \mathrm{OD}$ to these samples, one major compound is formed and signals for free tmeda were observed. NMR samples for protonolysis experiments were prepared by dissolving $2.8 \mu \mathrm{mol}$ of the respective complexes $\mathrm{G}_{\text {exp }} 14 \mathrm{a}, \mathrm{b}-(\mathrm{L})$ in a J. Young tube in $560 \mathrm{mg}$ of a stock solution prepared from 3.650 $\mathrm{g}$ of benzene- $d_{6}$ and $5.000 \mathrm{~g}$ of methanol- $d_{4}$. The sample was then transferred out of the glovebox and inserted into the preheated (313 $\mathrm{K})$ probe of a Varian Inova 400 spectrometer. Decay of the $\mathrm{Ni}-$ Me resonances of tmeda-complexes $\mathrm{G}_{\exp } 14 \mathrm{a}, \mathrm{b}-(\mathrm{tmeda})$ as well as generation of $\mathrm{CH}_{3} \mathrm{D}$ and the assumed $(\mathrm{N} \cap \mathrm{O})_{2} \mathrm{Ni}$ chelate were monitored by ${ }^{1} \mathrm{H}$ NMR experiments over $4-5$ half-life times $\left(t_{1 / 2}\right)$. Protonolysis of $\mathrm{G}_{\text {exp }} 14 \mathrm{a}, \mathrm{b}$-(pyridine) was monitored over ca. 1 halflife while only traces of protonolysis products were observed for $\mathrm{G}_{\mathrm{exp}} 14 \mathrm{a}, \mathrm{b}-\left(\mathrm{PPh}_{3}\right)$ after $5 \mathrm{~d}$ at $313 \mathrm{~K}$.

\section{Results and Discussion}

Ethylene vs Water Complexation. We shall now discuss how the complexation energy of water and ethylene is influenced by the substituents on the catalysts shown in Figure 1. The complexation energies $\Delta E(\mathrm{M}-\mathrm{L})$ of water and ethylene have been found as the negative of the energy required to remove $\mathrm{L}$ from the most stable form of the complexes in Figure 1 to produce $\mathrm{L}=\mathrm{H}_{2} \mathrm{O}, \mathrm{C}_{2} \mathrm{H}_{4}$, and the coordinativly unsaturated complex without $\mathrm{L}$ in its most stable form. A prime after the name of the activated complex will indicate an aqua complex, a double prime an olefin complex.

Grubbs' Systems. The binding of ethylene in the Grubbs and Brookhart systems has been investigated previously as part of the polymerization process, where the emphasis was on the effect of the growing alkyl chain on the ethylene binding. ${ }^{1 \mathrm{~b}, \mathrm{c}} \mathrm{We}$ have also studied the binding of ethylene and $\alpha$-substituted olefins to Grubbs- and Brookhart-type complexes in their copolymerization reactions. ${ }^{1 \mathrm{~d}, \mathrm{e}}$

The small size of the Grubbs system allowed us to carry out full quantum mechanical (QM) calculations based on DFT for all systems discussed, without resorting to partial use of molecular mechanics (MM). In this case the electronic effects in the phenyl group at the nitrogen are treated explicitly. For the structures involving only one functional group we examined the cis and trans isomers for both the water and ethylene complex, Figure 2.

Our study revealed that the cis structures, in which either water or ethylene are in the position cis to the oxygen, are more stable. These findings are in accordance with experi-

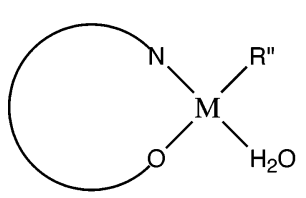

cis

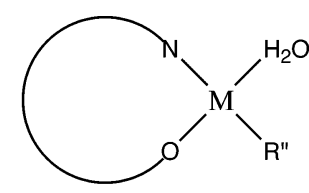

trans
Figure 2. cis and trans convention: cis, active binding site is cis to $\mathrm{O}$; trans, active binding site is trans to $\mathrm{O}$.

Table 1. Calculated $\pi$-Complexation Energies for Water and Ethylene in the Grubbs-Type Complexes

\begin{tabular}{|c|c|c|c|c|c|c|c|c|}
\hline name & $\mathbf{M}^{a}$ & $\mathrm{X}^{b}$ & $\mathrm{R}^{\prime}$ & $\mathrm{R}^{\prime \prime}$ & $\mathrm{R}$ & $\begin{array}{c}\Delta E(\mathrm{M}-\mathrm{L})^{c-e} \\
\mathrm{~L}=\mathrm{H}_{2} \mathrm{O}\end{array}$ & $\begin{array}{l}\Delta E(\mathrm{M}-\mathrm{L}) \\
\mathrm{L}=\mathrm{C}_{2} \mathrm{H}_{4}\end{array}$ & $\Delta \Delta E^{f}$ \\
\hline G1 & $\mathrm{Ni}$ & $\mathrm{H}$ & $\mathrm{H}$ & $\mathrm{CF}_{3}$ & $\mathrm{H}$ & -25.92 & -25.11 & -0.81 \\
\hline $\mathrm{G} 2$ & $\mathrm{Ni}$ & $\mathrm{H}$ & $\mathrm{H}$ & $\mathrm{Ph}$ & $\mathrm{H}$ & -23.25 & -26.03 & 2.78 \\
\hline G3 & $\mathrm{Ni}$ & $\mathrm{NO}_{2}$ & $\mathrm{H}$ & $\mathrm{Ph}$ & $\mathrm{H}$ & -24.64 & -27.48 & 2.84 \\
\hline G4 & $\mathrm{Ni}$ & $\mathrm{H}$ & $\mathrm{H}$ & ${ }^{\mathrm{i}} \mathrm{Pr}$ & $\mathrm{H}$ & -5.86 & -9.09 & 3.23 \\
\hline G5 & $\mathrm{Ni}$ & $\mathrm{H}$ & $\mathrm{H}$ & $\mathrm{Ph}$ & $\mathrm{Me}$ & -17.15 & -20.65 & 3.5 \\
\hline G6 & $\mathrm{Ni}$ & $\mathrm{H}$ & ${ }^{t} \mathrm{Bu}$ & $\mathrm{Ph}$ & $\mathrm{H}$ & -22.95 & -27.46 & 4.51 \\
\hline G7 & $\mathrm{Ni}$ & $\mathrm{NO}_{2}$ & $\mathrm{H}$ & $\mathrm{Me}$ & $\mathrm{H}$ & -26.29 & -31.41 & 4.82 \\
\hline G8 & $\mathrm{Ni}$ & $\mathrm{H}$ & $\mathrm{H}$ & $\mathrm{Me}$ & $\mathrm{H}$ & -25.28 & -31.05 & 5.77 \\
\hline G9 & $\mathrm{Ni}$ & $\mathrm{H}$ & ${ }^{t} \mathrm{Bu}$ & $\mathrm{Me}$ & $\mathrm{H}$ & -24.29 & -31.03 & 6.74 \\
\hline G10 & $\mathrm{Ni}$ & $\mathrm{H}$ & $\mathrm{H}$ & $\mathrm{Me}$ & $\mathrm{Me}$ & -16.11 & -23.02 & 6.91 \\
\hline G11 & $\mathrm{Ni}$ & $\mathrm{H}$ & $\mathrm{H}$ & $\mathrm{Me}$ & ${ }^{\mathrm{i} P r}$ & -24.06 & -31.60 & 7.54 \\
\hline G12 & $\mathrm{Ni}$ & $\mathrm{H}$ & $\mathrm{H}$ & $\mathrm{Ph}$ & ${ }^{\mathrm{i}} \mathrm{Pr}$ & -18.79 & -27.03 & 8.24 \\
\hline G13 & $\mathrm{Pd}$ & $\mathrm{H}$ & $\mathrm{H}$ & $\mathrm{Me}$ & $\mathrm{H}$ & -25.18 & -36.76 & 11.58 \\
\hline
\end{tabular}

${ }^{a}$ Metal. ${ }^{b}$ For labeling of the substituents on the Grubbs catalyst see Figure 1a. ${ }^{c}$ Energies in $\mathrm{kcal} \mathrm{mol}^{-1} .{ }^{d}$ Complexation energies. $^{e}$ Toluene was used as the solvent. ${ }^{f} \Delta \Delta E=\Delta E\left(\mathrm{M}-\mathrm{H}_{2} \mathrm{O}\right)-\Delta E\left(\mathrm{M}-\mathrm{C}_{2} \mathrm{H}_{4}\right)$.

mentally determined solid-state structures of complexes $\mathrm{R}^{\prime \prime}=\mathrm{Me}$ and $\mathrm{L}=$ acetonitrile ${ }^{8 \mathrm{c}}$ or pyridine.$^{5 \mathrm{~g}}$ For water the cis isomer is more stable by around $8 \mathrm{kcal} \mathrm{mol}^{-1}$, while in the case of ethylene the difference is less than $2 \mathrm{kcal} \mathrm{mol}^{-1}$. This is to be expected since the trans labilizing ability of $\mathrm{H}_{2} \mathrm{O}$ is much smaller than ethylene. The reported results are for the cis structures. The complexation energies are calculated relative to the uncoordinated activated complex of lowest energy with one empty ligand site and collected in Table 1.

We shall start our discussion of the Grubbs system by considering the substitution of $\mathrm{R}^{\prime \prime}=\mathrm{CH}_{3}(\mathbf{G 8})$ by other groups while $\mathrm{X}, \mathrm{R}^{\prime}$, and $\mathrm{R}$ of Figure $1 \mathrm{a}$ are represented by hydrogen and $\mathrm{M}=\mathrm{Ni}$. The replacement of $\mathrm{CH}_{3}$ by $\mathrm{CF}_{3}$ in the $\mathrm{R}^{\prime \prime}$ position $(\mathbf{G 1})$ results in a substantial decrease in $-\Delta E(\mathrm{M}-\mathrm{L})$ for $\mathrm{L}=\mathrm{C}_{2} \mathrm{H}_{4}$ and a smaller increase for $\mathrm{L}=$ $\mathrm{H}_{2} \mathrm{O}$. The replacement of $\mathrm{CH}_{3}$ by $\mathrm{CF}_{3}$ is the only substitution where the $-\Delta E(\mathrm{M}-\mathrm{L})$ binding energy was calculated to be larger for $\mathrm{H}_{2} \mathrm{O}$. The group $\mathrm{CF}_{3}$ has a strong electronwithdrawing effect that will make the metal harder by accepting more of its d-electron density. This will decrease the repulsive interaction of the lone pair of oxygen in $\mathrm{H}_{2} \mathrm{O}$ with the metal and thus stabilize the $\mathrm{M}-\mathrm{H}_{2} \mathrm{O}$ bond. On the other hand, the electron-withdrawing ability of $\mathrm{CF}_{3}$ will disfavor the back-donation of electron density from the metal to the $\pi^{*}$ orbital on ethylene and destabilize the $\mathrm{M}-\mathrm{C}_{2} \mathrm{H}_{4}$ bond.

Phenyl complexes $\left(\mathrm{R}^{\prime \prime}=\mathrm{Ph}\right)$ have been employed as catalyst precursors, also for emulsion polymerization. Having a phenyl group in the $\mathrm{R}^{\prime \prime}$ position (G2) reduces the $-\Delta E(\mathrm{M}-\mathrm{L})$ bond energy for $\mathrm{L}=\mathrm{H}_{2} \mathrm{O}$ and especially $\mathrm{L}=$ $\mathrm{C}_{2} \mathrm{H}_{4}$. This is understandable since $\mathrm{R}^{\prime \prime}=\mathrm{C}_{5} \mathrm{H}_{6}$ is less 


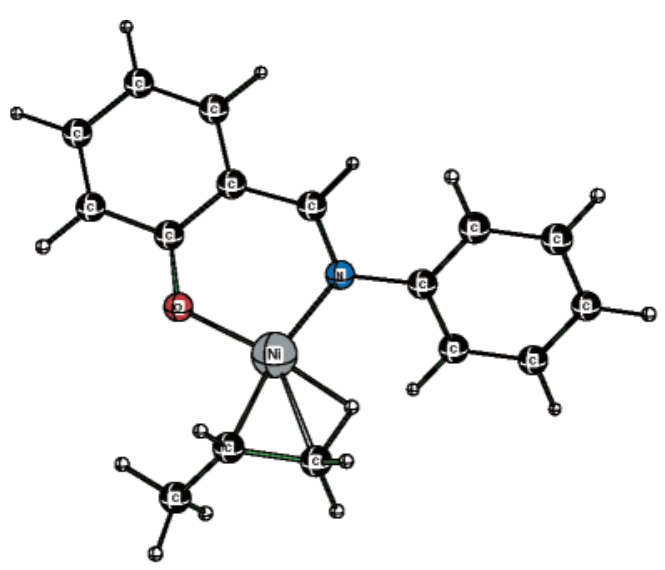

Activated precursor complex G4

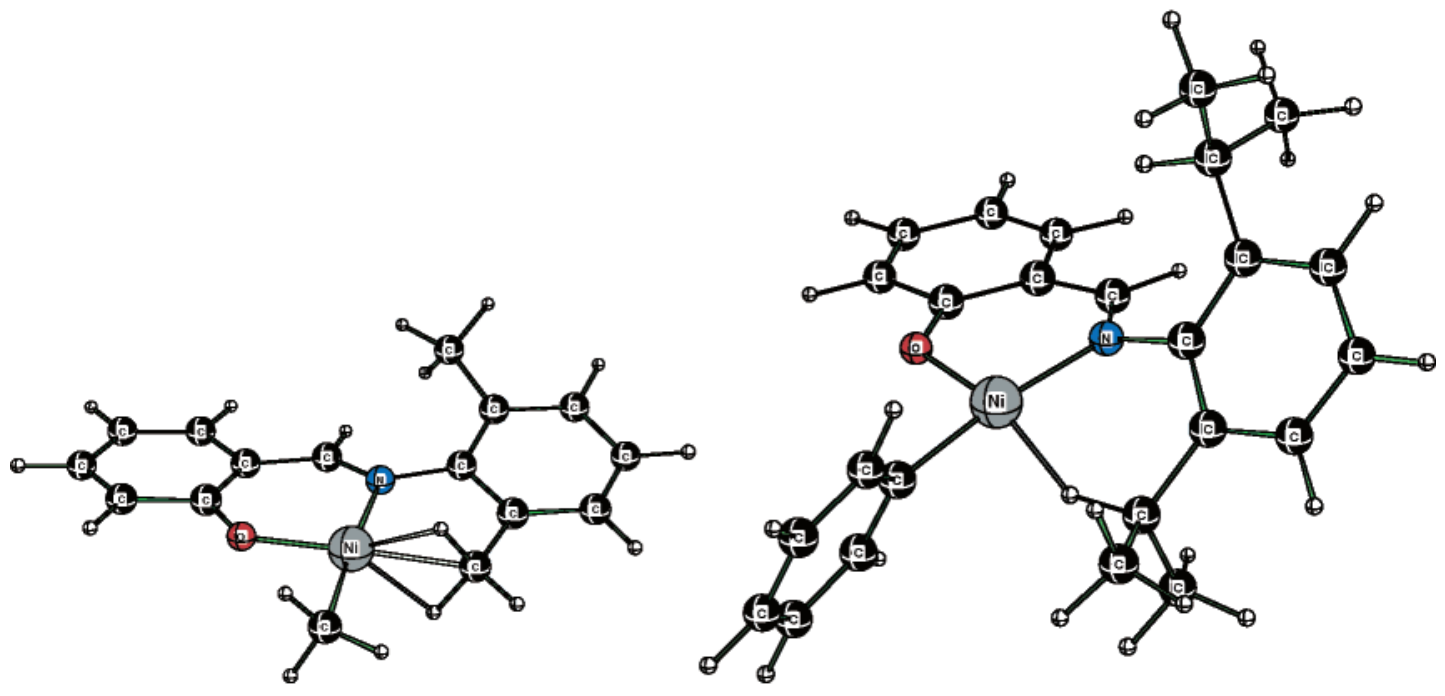

Activated precursor complex G10

\section{Activated precursor complex G12}

Figure 3. Activated coordinatively unsaturated precursor complexes for Grubbs catalysts with $\beta$-agostic interactions.

electron-donating and sterically more demanding. The formation of the cis isomers of the water and ethylene complexes would also require that the $\mathrm{R}^{\prime \prime}$ phenyl is closer to the N-phenyl ring. Our calculations however do not show any steric effects, for example, the cis-G2' aqua complex is more stable by $7.7 \mathrm{kcal} \mathrm{mol}^{-1}$ over the trans complex.

Isopropyl complexes are of interest as models for the growing chain in ethylene polymerization in which branching occurs via "chain running". When $\mathrm{R}^{\text {" }}=\operatorname{Pr}(\mathbf{G 4})$, both binding energies are very small due to the agostic interactions between $\beta$-hydrogens on the ${ }^{i} \operatorname{Pr}$ group and the metal center in the activated coordinatively unsaturated complex, Figure 3 . The $\beta$-agostic interaction leads to the stretching of the $\mathrm{C}-\mathrm{H}$ bond $(\mathrm{R}=1.21 \AA)$ on the $\beta$ carbon atom and the formation of a $\mathrm{Ni}-\mathrm{H}$ link $(\mathrm{R}=1.60 \AA)$. This activated complex is not very susceptible toward ligand binding with complexation energies of only $-9.1 \mathrm{kcal} \mathrm{mol}^{-1}$ for ethylene and $-5.9 \mathrm{kcal} \mathrm{mol}^{-1}$ for water, Table 1 . Another contribution that can explain the low binding energies is the steric repulsion between the iPr group and the phenyl ring on the $\mathrm{N}$ atom. For the trans isomer of the ethylene complex G4" or in the case when the phenyl ring is substituted by $\mathrm{H}$, the bonding energies are around $10 \mathrm{kcal} \mathrm{mol}^{-1}$ higher. ${ }^{11 \mathrm{~b}, \mathrm{~h}}$
We shall now turn to the substitution of $\mathrm{R}=\mathrm{H}$ on the aryl ring attached to the nitrogen with other groups such as $\mathrm{R}=\mathrm{CH}_{3}$ and ${ }^{\mathrm{i}} \mathrm{Pr}$. The complexation energies we get for the ethylene complex are several $\mathrm{kcal} \mathrm{mol}^{-1}$ lower for $\mathrm{R}=\mathrm{CH}_{3}$ than when $\mathrm{R}=\mathrm{H}$. This reduction is very pronounced with the methyl groups, where two of the methyl hydrogens form agostic bonds with the metal center in the coordinatively unsaturated precursor complex, Figure 3 . When $\mathrm{R}=$ Me this led to the rotation of the associated phenyl ring into the plane of the complex, decreasing the dihedral angle from around $40^{\circ}$ (G8) to $9^{\circ}$ (precursor complex G10), see Figure 3. In the case of ${ }^{i} \mathrm{Pr}$ groups the phenyl ring is raised above the plane of the complex and the dihedral angle with the plane remains at $40^{\circ}$ (G12). Thus, the complex accomplishes the formation of $\mathrm{Ni}-\mathrm{H}$ bonds without the increase in energy associated with the torsion around the dihedral angle. The length of the $\mathrm{Ni}-\mathrm{H}$ bonds is between 1.69 (G10) and $1.80 \AA$ (G12).

The two $\mathrm{Ni}-\mathrm{H}$ bonds (when $\mathrm{R}=\mathrm{Me}$ ) stabilize the coordinatively unsaturated precursor complex G10 and reduce the binding energies for water and ethylene. When $\mathrm{R}={ }^{i} \mathrm{Pr}$, the $\beta$-agostic bond is somewhat weaker and the $\Delta E(\mathrm{M}-\mathrm{L})$ bonding energies are not reduced to the same 
Table 2. Calculated Complexation Energies for Water and Ethylene in the Brookhart Type Complexes

\begin{tabular}{ccccccc}
\hline & & & \multicolumn{3}{c}{$\Delta E(\mathrm{M}-\mathrm{L})^{c-e}$} & $\Delta E(\mathrm{M}-\mathrm{L})$ \\
name & $\mathrm{M}^{a}$ & $\mathrm{R}^{\prime \prime b}$ & $\mathrm{R}$ & $\mathrm{L}=\mathrm{H}_{2} \mathrm{O}$ & $\mathrm{L}=\mathrm{C}_{2} \mathrm{H}_{4}$ & $\Delta \Delta E^{f}$ \\
\hline $\mathrm{B} 1$ & $\mathrm{Pd}$ & $\mathrm{Me}$ & $\mathrm{Me}$ & -28.92 & -35.22 & 6.30 \\
$\mathrm{~B} 2$ & $\mathrm{Pd}$ & $\mathrm{Me}$ & $\mathrm{i} \mathrm{Pr}$ & -24.05 & -34.74 & 8.42 \\
$\mathrm{~B} 3$ & $\mathrm{Ni}$ & $\mathrm{Me}$ & $\mathrm{Me}$ & -31.15 & -34.58 & 3.43
\end{tabular}

${ }^{a}$ Metal. ${ }^{b}$ For labeling of the substituents on the Brookhart catalyst see Figure 1b. ${ }^{c}$ Energies in $\mathrm{kcal} \mathrm{mol}^{-1} .{ }^{d}$ Complexation energies. ${ }^{e}$ Toluene was used as the solvent. ${ }^{f} \Delta \Delta E=\Delta E\left(\mathrm{M}-\mathrm{H}_{2} \mathrm{O}\right)-\Delta E\left(\mathrm{M}-\mathrm{C}_{2} \mathrm{H}_{4}\right)$.

degree as for $\mathrm{R}=\mathrm{CH}_{3}$. In fact, ethylene binds slightly stronger to the $\mathrm{R}={ }^{\mathrm{i}} \operatorname{Pr}$ systems $(\mathbf{G 1 1}, \mathbf{G 1 2})$ than the generic systems with $\mathrm{R}=\mathrm{H}$, while water always forms weaker bonds. This could be due to the positive induction effect of the $\mathrm{P}$ Pr groups that increases the ability of the metal center to back-donate electron density to the olefin, which also makes the electron donation from water less favorable. Out of all compounds considered based on nickel, complex G12 is the most promising in terms of olefin preference with $\Delta E_{\pi}=8.24$ $\mathrm{kcal} \mathrm{mol}{ }^{-1}$.

We discuss finally the substitution of the $\mathrm{X}=\mathrm{H}$ and $\mathrm{R}^{\prime}=\mathrm{H}$ groups of the aryl on oxygen with $\mathrm{X}=\mathrm{NO}_{2}(\mathbf{G} 3$ and G7) or $\mathrm{R}^{\prime}={ }^{\mathrm{t}} \mathrm{Bu}$ (G6 and G9). The acceptor $\mathrm{NO}_{2}$ group increases the complexation energies for both water and ethylene, while the difference between them depends on the $\mathrm{R}^{\prime \prime}$ ligand. The 'Bu group has a very small positive effectit disfavors the complexation with water and increases the difference in the complexation energies.

In the last example of the monosubstituted Grubbs systems we considered replacing $\mathrm{Ni}$ for Pd. In this case the complexation energy for water is almost unchanged, whereas ethylene binds more strongly by about $5.7 \mathrm{kcal} \mathrm{mol}^{-1}$. This is due to the easier back-donation to ethylene by $\mathrm{Pd}(\mathrm{II})$. This result is in qualitative agreement with the theoretical study ${ }^{30}$ of ethylene binding to $\mathrm{M}\left(\mathrm{NH}_{3}\right)_{x} \mathrm{Cl}_{3-x}$ systems $\left(\mathrm{M}=\mathrm{Ni}^{2+}\right.$, $\left.\mathrm{Pd}^{2+}, \mathrm{Pt}^{2+}\right)$ where the binding energy for the neutral $\mathrm{M}\left(\mathrm{NH}_{3}\right)$ $\mathrm{Cl}_{2}$ was $8.9 \mathrm{kcal} \mathrm{mol}^{-1}$ more favorable for Pd. The Pd-based Grubbs system exhibits the highest olefin preference with $\Delta E_{\pi}$ of about $11.6 \mathrm{kcal} \mathrm{mol}^{-1}$, which is even slightly higher than the values observed for the Brookhart system (see below).

The Brookhart System. The olefin complexation in the Brookhart system has been studied extensively in a recent paper. ${ }^{31}$ Here we concentrated on the complexation energies of the cationic compounds in which all $\mathrm{R}$ groups are the same (i.e., either $\mathrm{Me}$ or ${ }^{~} \mathrm{Pr}$ ) and $\mathrm{R}^{\prime \prime}=\mathrm{Me}$ for both $\mathrm{Ni}$ an $\mathrm{Pd}$. The positive charge on the complex affects most strongly the ability of the metal center to accept electron density from either water or ethylene, while the back-donation ability of the metal is somewhat reduced by the charge. In addition, positive charge on the metal will interact favorably with the water dipole. The complexation energies for the Brookhart systems are collected in Table 2.

(30) Stromberg, S.; Svensson, M.; Zetterberg, K. Organometallics 1997, 16,3165 .

(31) Woo, T. K.; Blochl, P. E.; Ziegler, T. J. Phys. Chem. A 2000, 104, 121.

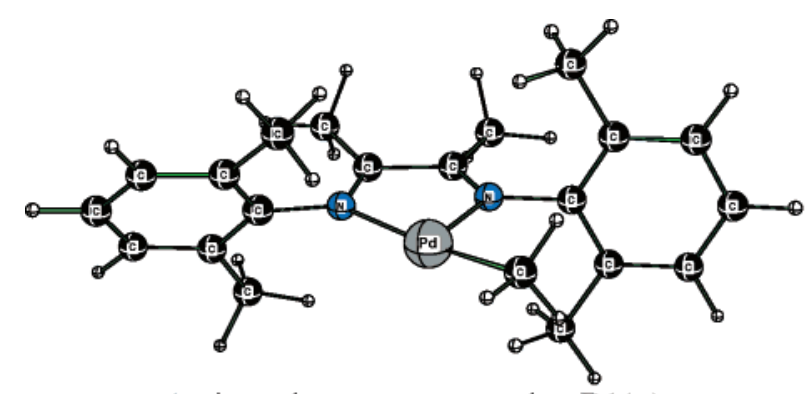

Activated precursor complex B1(+)

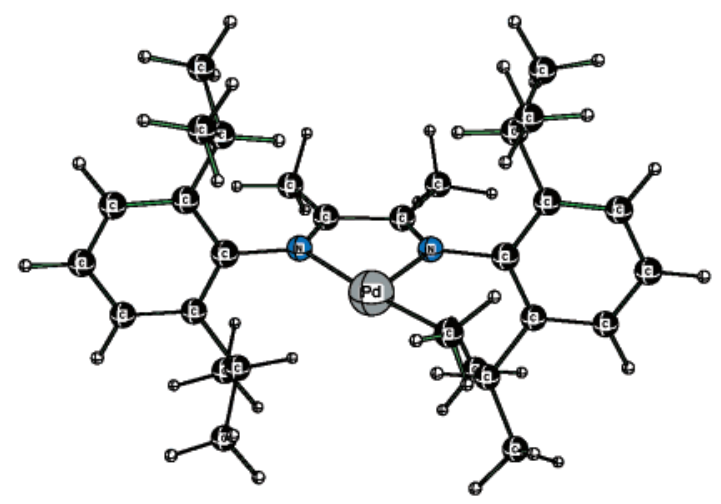

Activated precursor complex B2(+)

Figure 4. Activated coordinatively unsaturated precursor complexes for Brookhart catalysts.

The size of the Brookhart system barred us from conducting a complete investigation based on full QM calculations. Instead, use was made of a combined quantum mechanical and molecular mechanical method (QM/MM); see Computational Method section. This method does not allow us to model the formation of a metal $-\mathrm{H}$ agostic bond when the hydrogen atom is part of the $\mathrm{N}$-phenyl group, since $\mathrm{N}$-phenyl is described by MM. Thus, to explore the feasibility for this kind of bonding, we performed a full QM calculation on the precursor complexes (B1, B2, and B3) (Figure 4). We were not able to locate any minima with a $\mathrm{M}-\mathrm{H}$ agostic bond. We contribute this to steric factors - that is, the presence of the Me groups on the far side of the $\mathrm{N}-\mathrm{C}-$ $\mathrm{C}-\mathrm{N}$ ring will hinder the rotation of the phenyl ring and keep the 2,6-Me groups out of the plane of the complex and away from the metal. It is perhaps surprising that the 2,6${ }^{i}$ Pr groups in $\mathbf{B} 2$ as well are unable to interact with the metal given that in the Grubbs system G12 agostic bonds are formed between $\mathrm{R}={ }^{\mathrm{i}} \mathrm{Pr}$ and the metal.

It is worthwhile to mention two recent experimental studies ${ }^{12 b, c}$ where the activation of a $\mathrm{C}-\mathrm{H}$ bond on a side chain in the Brookhart system leads to the elimination of the methyl ligand as methane accompanied by the formation of a cyclic structure. This is a type of metalation process. However, we shall not discuss it any further since it is not specific for polymerization in an aqueous system.

As there is no agostic bond formation here, any difference in the binding energies for Me and ${ }^{\mathrm{P}} \mathrm{Pr}$ substituents can be explained as the combination of sterics and (inductive) electronic effects. In the case of $\mathrm{R}={ }^{i} \operatorname{Pr}(\mathbf{B} 2)$, water is particularly destabilized due to the strong electron donation 
Table 3. Calculated Complexation Energies for Water and Ethylene in the $\mathrm{O}-\mathrm{P}$ Chelate Complexes

\begin{tabular}{cccccc}
\hline & & \multicolumn{3}{c}{$\Delta E(\mathrm{M}-\mathrm{L})^{c-e}$} & $\Delta E(\mathrm{M}-\mathrm{L})$ \\
name & $\mathrm{M}^{a}$ & $\mathrm{R}^{\prime \prime b}$ & $\mathrm{~L}=\mathrm{H}_{2} \mathrm{O}$ & $\mathrm{L}=\mathrm{C}_{2} \mathrm{H}_{4}$ & $\Delta \Delta E^{f}$ \\
\hline $\mathrm{P} 1$ & $\mathrm{Pd}$ & $\mathrm{Ph}$ & -38.22 & -44.33 & 6.11 \\
$\mathrm{P} 2$ & $\mathrm{Ni}$ & $\mathrm{Ph}$ & -41.56 & -46.78 & 5.22
\end{tabular}

${ }^{a}$ Metal. ${ }^{b}$ For labeling of the substituents on the $\mathrm{O}-\mathrm{P}$ chelate catalyst, see Figure 1c. ${ }^{c}$ Energies in $\mathrm{kcal} \mathrm{mol}{ }^{-1} .{ }^{d}$ Complexation energies. ${ }^{e}$ Toluene was used as the solvent. ${ }^{f} \Delta \Delta E=\Delta E\left(\mathrm{M}-\mathrm{H}_{2} \mathrm{O}\right)-\Delta E\left(\mathrm{M}-\mathrm{C}_{2} \mathrm{H}_{4}\right)$.

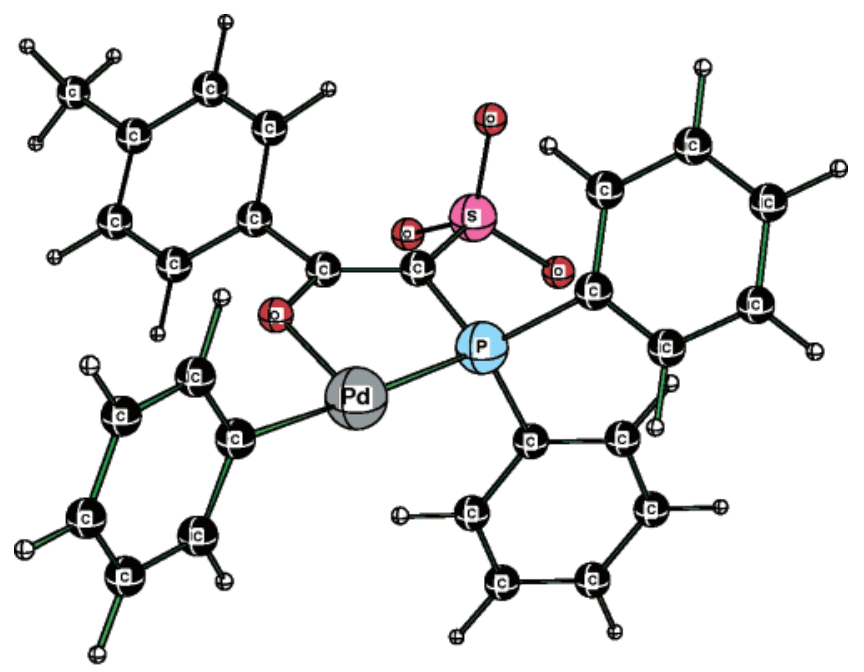

\section{Activated precursor complex P1(-)}

Figure 5. Activated coordinatively unsaturated precursor complexes for the $\mathrm{O}-\mathrm{P}$ chelate system.

from the ${ }^{i} \operatorname{Pr}$ groups and the steric repulsion. Despite the more favorable back-donation to ethylene the steric effect also leads to a slightly lower complexation energy for this ligand. In the case of the methyl complex B1 there is less steric repulsion and less electron donation to the metal. This serves to bring the complexation energies of water and ethylene closer, thus reducing the binding selectivity.

Changing the metal from $\mathrm{M}=\mathrm{Pd}$ in $\mathbf{B 1}$ to $\mathrm{M}=\mathrm{Ni}$ in $\mathbf{B 3}$ increases the water binding energy by more than $2 \mathrm{kcal} \mathrm{mol}^{-1}$ as nickel is more oxophilic since the occupied d-orbital overlaps less with the occupied oxygen lone pair. At the same time the ethylene complexation energy is reduced slightly.
The results here are comparable to the ones for the Grubbs system without agostic bonds.

O-P Chelate System. Finally, we briefly examined the anionic $\mathrm{O}-\mathrm{P}$ chelate system for both $\mathrm{Ni}$ and $\mathrm{Pd}$, Table 3 . Here too the system was separated into $\mathrm{QM}$ and $\mathrm{MM}$ regions, see computational details. Shown below in Figure 5 is the activated anionic complex with $\mathrm{Pd}$.

The high complexation energies of more than $30 \mathrm{kcal}$ $\mathrm{mol}^{-1}$ for water and $40 \mathrm{kcal} \mathrm{mol}^{-1}$ for ethylene were also observed in the gas phase, as the solvent effects accounted for only about $3 \mathrm{kcal} \mathrm{mol}^{-1}$ in the binding energies, Table 3 . The negative charge is concentrated on the terminal $\mathrm{O}$ atoms, which allows the metal center to act as a good electron acceptor. Thus, we observe an increase in the complexation energies for both water and ethylene. Despite these high energies the selectivity toward ethylene binding is similar to the other two systems.

Catalyst Hydrolysis. Hydrolysis resulting in irreversible loss of the metal-bound methyl or phenyl group $\left(\mathrm{R}^{\prime \prime}=\mathrm{Me}\right.$ or $\mathrm{Ph}$ ) can affect the catalyst precursor during the handling prior to the polymerization reaction, e.g., during preparation of catalyst precursor miniemulsions. ${ }^{5 \mathrm{~d}, 6 \mathrm{~b}}$ Equally, in the active species during polymerization, hydrolysis of the growing chain $\left(\mathrm{R}^{\prime \prime}=\right.$ alkyl) can result in irreversible deactivation. Here we have examined two mechanisms for the hydrolysis and looked at the factors that influence the barrier for that process.

Grubbs Catalyst Hydrolysis. In the first hydrolysis mechanism which we studied for the Grubbs system, Figure $6 \mathrm{a}$, water directly attacks the ethylene complex $\mathbf{1}$ by first forming a weak associate $\mathbf{2}$ where $\mathrm{H}_{2} \mathrm{O}$ occupies the axial position. The energy diagram for the mechanism is shown in Figure 7.

Solvent effects disfavor complexation of $\mathrm{H}_{2} \mathrm{O}$ perpendicular to the coordination plane of the complex and the complexation energy for the axial water molecule is zero, Figure 7. In the transition state structure TS[2-3], Figure 8a, the $\mathrm{C}-\mathrm{H}$ bond length is $1.25 \AA$ and the ethylene moiety sits below the plane of the complex. The barrier for this process is $26.3 \mathrm{kcal} \mathrm{mol}^{-1}$ in solution. In a modification of this mechanism we considered a bridge of two water

a)

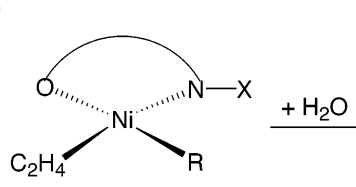

1

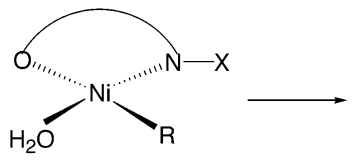

4

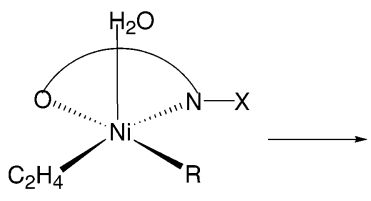

2

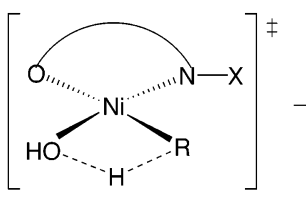

TS[4-5]

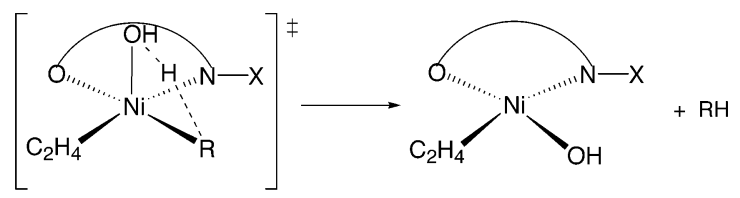

TS[2-3] 3

Figure 6. Hydrolysis mechanisms for the Grubbs system (a) external water attack and (b) in the plane attack. 
$\Delta \mathbf{E}(\mathbf{k c a l} / \mathbf{m o l})$

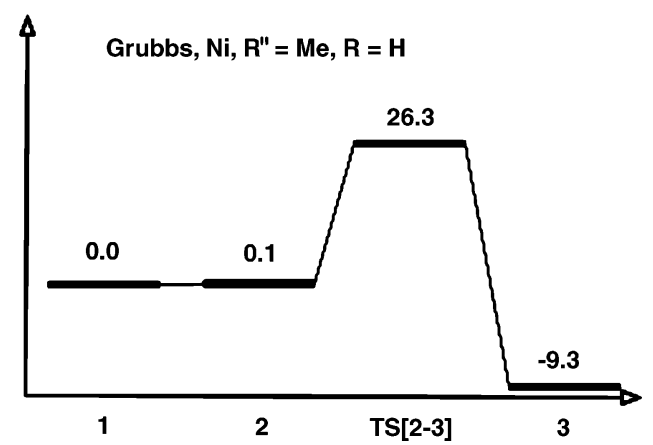

Figure 7. Energy diagram for the external hydrolysis of the generic Grubbs catalysts. Energies in $\mathrm{kcal} \mathrm{mol}^{-1}$ in toluene.

molecules for the hydrolysis in which the first water supplies the $\mathrm{OH}$ group to the metal and the second water the $\mathrm{H}$ to the alkyl group. We obtained a barrier of $24.1 \mathrm{kcal} \mathrm{mol}^{-1}$ for this process. Thus, the use of a water bridge is not likely to lower the barrier for this mechanism when one takes into account possible entropic costs in forming the bridge (see below).

In the second mechanism that we investigated, water first replaces ethylene in the plane of the complex and the hydrogen transfer takes place in the same plane, Figure $6 \mathrm{~b}$. This pathway seems plausible in view of the small energy required for water to replace ethylene (see Table 1). The energy diagram for the generic Grubbs catalyst is shown in Figure 9a.

The barrier that corresponds to the transition state structure TS[4-5], Figure 8b, is $16.8 \mathrm{kcal} \mathrm{mol}^{-1}$ in solution. Here the bond length of the $\mathrm{C}-\mathrm{H}$ linkage is $1.30 \AA$ which is very similar to the one observed in TS[2-3]. The product of the reaction is the tri-coordinated hydroxy complex $\mathbf{6}$, which could dimerize to a $\mu$-hydroxo bridged dimer. ${ }^{32}$

The mechanism outlined in Figure $6 \mathrm{~b}$ is similar to the reverse of methane $\mathrm{C}-\mathrm{H}$ activation by $\sigma$-bond metathesis. The hydrogen atom being transferred to the methyl group does not stay in the plane of the complex during the entire transition. For $\mathrm{C}-\mathrm{H}$ bond distances below $1.30 \AA$ the $\mathrm{C}-\mathrm{H}$ bond is normal to the plane of the complex with $\mathrm{Ni}$ forming a $\sigma$-adduct with the $\mathrm{C}-\mathrm{H}$ bond, Figure 10 .

Preliminary experimental investigations ${ }^{33}$ toward the hydrolysis process were performed with salicylaldiminato complexes $\mathbf{G}_{\mathbf{e x p}} \mathbf{1 4 a}, \mathbf{b}-(\mathbf{L})\left[\mathbf{a}: \mathrm{R}=3,5-\left(\mathrm{CF}_{3}\right) \mathrm{C}_{6} \mathrm{H}_{3}, \mathbf{b}: 3,5-\right.$ xylyl; $\mathrm{R}^{\prime}=\mathrm{X}=\mathrm{I}: \mathrm{R}^{\prime \prime}=\mathrm{Me} ; \mathrm{L}=\mathrm{Me}_{2} \mathrm{NCH}_{2} \mathrm{CH}_{2} \mathrm{NMe}_{2}$ (tmeda) $]^{5 g}$ (Figure 11) which in benzene- $d_{6}$ solution exist as

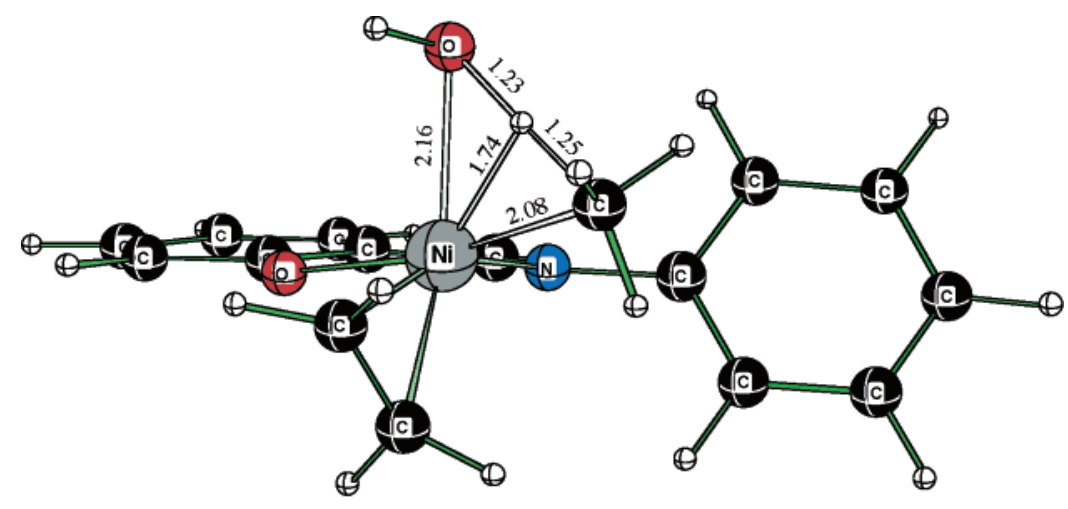

a) $\mathrm{TS}[2-3]$

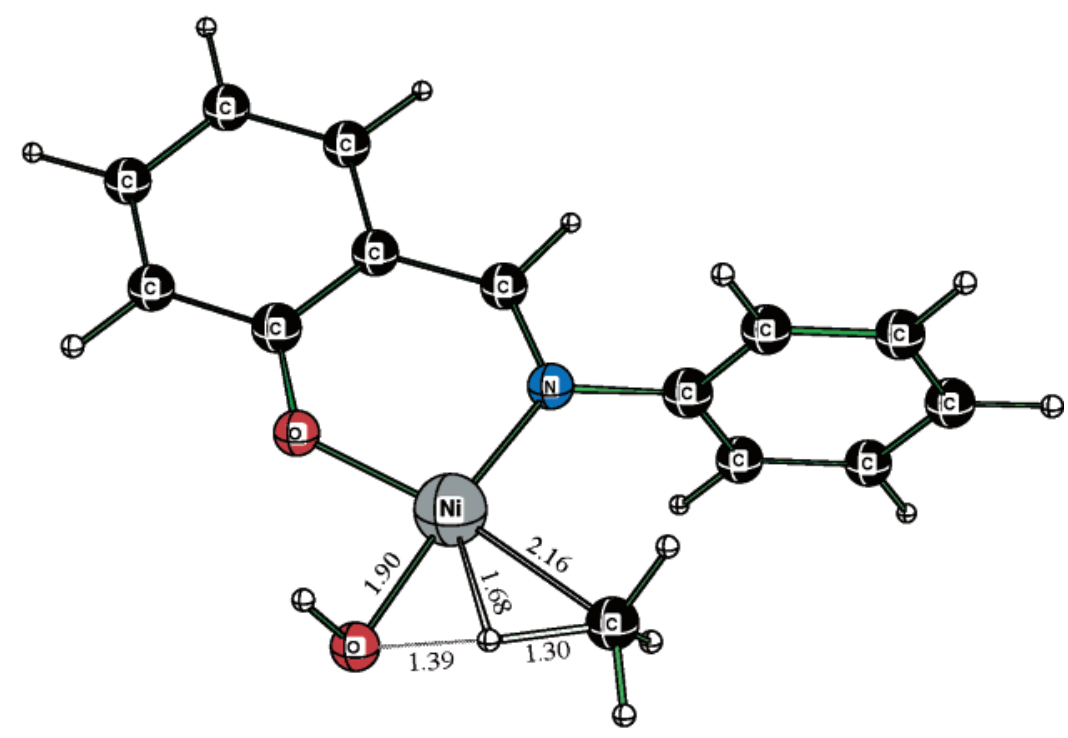

b)

Figure 8. Geometry of the transition state structures (a) for external hydrolysis and (b) for hydrolysis in the plane, for the generic Grubbs catalyst. 
a)

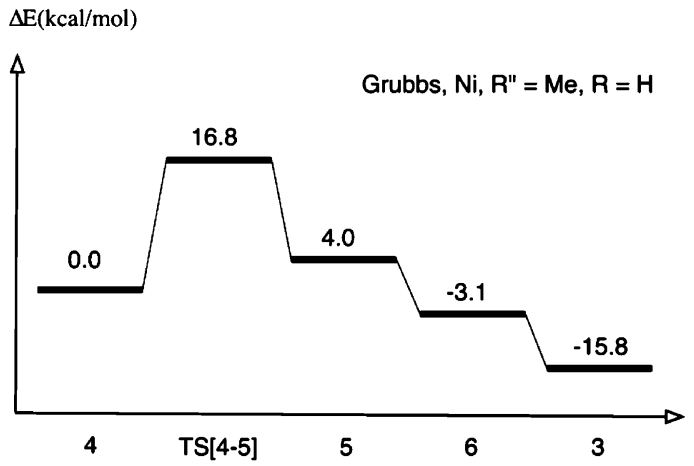

c)

$\Delta \mathrm{E}(\mathrm{kcal} / \mathrm{mol})$

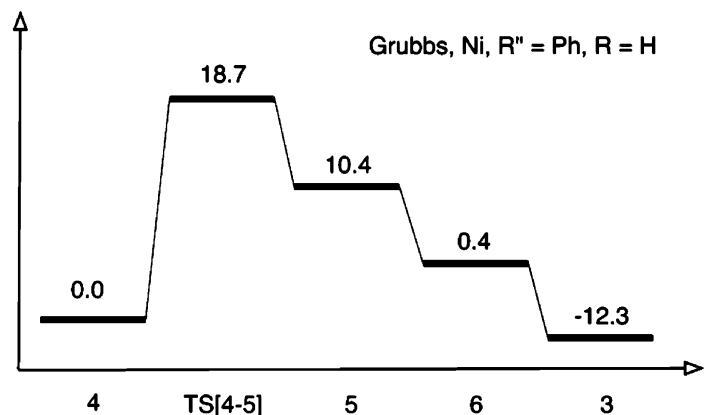

b)

$\Delta \mathrm{E}(\mathrm{kcal} / \mathrm{mol})$

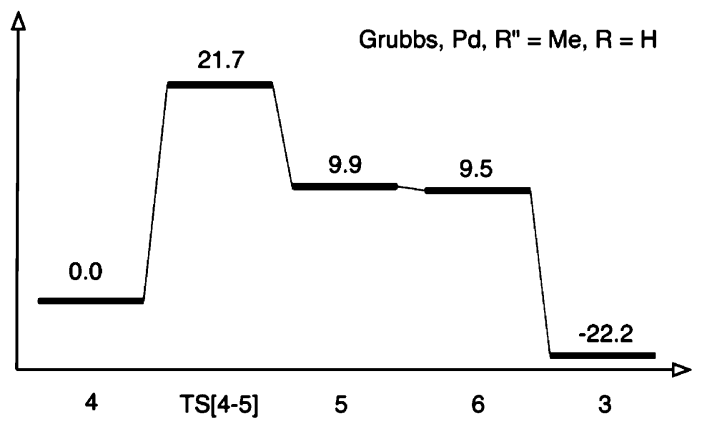

d)

$\Delta \mathrm{E}(\mathrm{kcal} / \mathrm{mol})$

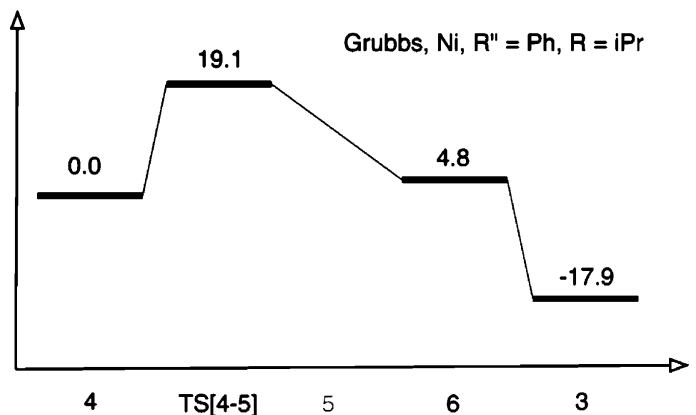

Figure 9. Energy diagram for the hydrolysis of the Grubbs catalysts. Energies in $\mathrm{kcal} \mathrm{mol}^{-1}$ in toluene.

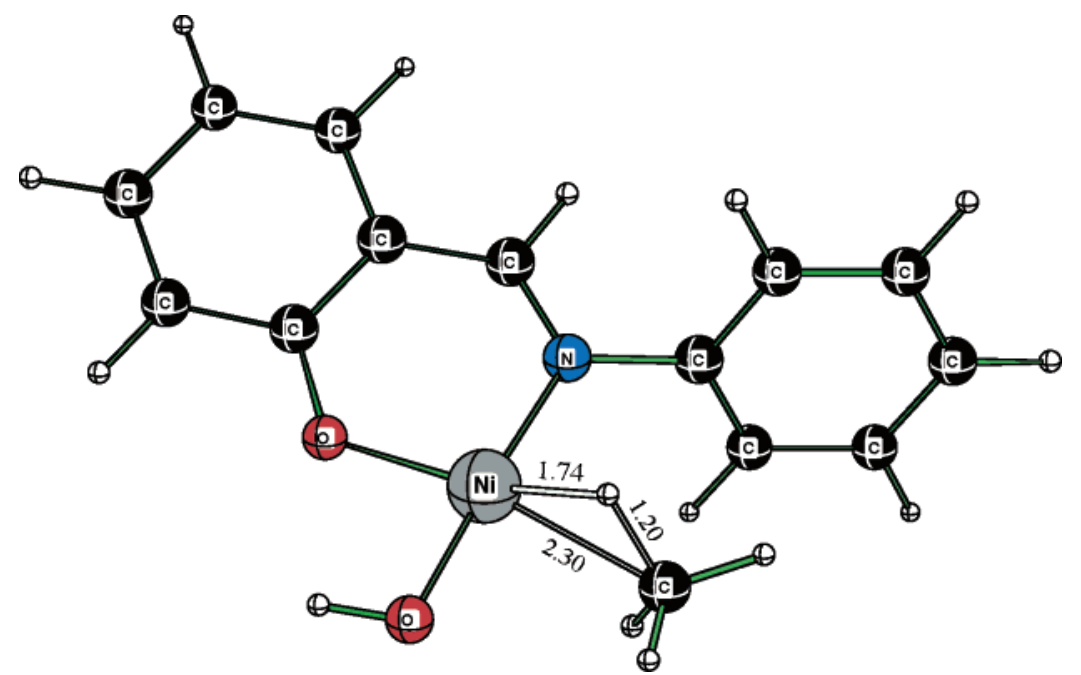

Figure 10. Intermediate structure with $\mathrm{R}(\mathrm{C}-\mathrm{H})=1.20 \AA$ for the in the plane hydrolysis of the generic Grubbs system.

isomeric mixtures. As these complexes are water-insoluble and only sparingly soluble in methanol, protonolysis of $\mathbf{G}_{\text {exp }} \mathbf{1 4 a , b - ( t m e d a ) ~ w a s ~ s t u d i e d ~ b y ~}{ }^{1} \mathrm{H}$ NMR experiments in ca. $5 \mathrm{mM}$ solutions of benzene- $d_{6} / \mathrm{CD}_{3} \mathrm{OD}$ mixtures (ca 2.6 $\mathrm{M}$ in benzene- $d_{6} / 8.4 \mathrm{M}$ in $\left.\mathrm{CD}_{3} \mathrm{OD}\right)$ at initially $298 \mathrm{~K}$. Under these conditions one isomer in each case accounts for more than $90 \%$ of the sample on the basis of the integration of the $\mathrm{Ni}-\mathrm{Me}$ and the resonances of the backbone ligand while the signals of tmeda fit that of free tmeda. We therefore

(32) Svejda, S. A.; Johnson, L. K ; Brookhart, M. J. Am. Chem. Soc. 1999, $121,10634$.

(33) DeKock, R. L.; Hristov, I. H.; Andersen, G. D. W.; GöttkerSchnetmann, I.; Mecking, S.; Ziegler, T. Organometallics 2005, 24, 2679-2687. assume that $\mathrm{CD}_{3} \mathrm{OD}$ displaces tmeda on the Ni center in an equilibrium reaction. Over time gradual evolution of $\mathrm{CH}_{3} \mathrm{D}$ is observed in these samples as evidenced by a 1:1:1 triplet with ${ }^{2} J_{\mathrm{H}-\mathrm{D}}=$ ca. $1.9-2.0 \mathrm{~Hz}$ at $0.18 \mathrm{ppm}$ while the resonances corresponding to the $\mathrm{Ni}-\mathrm{Me}$ complexes disappear and one new set of resonances for the salicylaldiminato ligand bond to $\mathrm{Ni}$ grows in. We have assigned the newly formed $\mathrm{Ni}$ complexes as $(\mathrm{N} \cap \mathrm{O})_{2} \mathrm{Ni}$ but cannot rule out a methoxy brigded dimer $(\mathrm{N} \cap \mathrm{O}) \mathrm{Ni}\left(\mu-\mathrm{OCD}_{3}\right)_{2} \mathrm{Ni}(\mathrm{N} \cap \mathrm{O})(\mathrm{Scheme}$ 2). ${ }^{34}$

(34) X-ray diffraction analysis of crystals obtained from the NMR tube experiments of Gexp1a-(tmeda) support the formation of $(\mathrm{N} \cap \mathrm{O})_{2} \mathrm{Ni}$; however, the quality of the crystals was poor. 


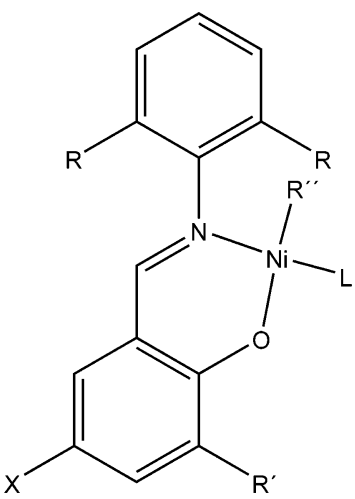

$$
\begin{aligned}
& \mathbf{G}_{\exp } 14 a-(L): R^{\prime}=X=I, R^{\prime \prime}=M e, R=3,5 \text {-bis(trifluoromethyl)phenyl, } L=\text { tmeda, pyridine, } P(P h)_{3} \\
& \mathbf{G}_{\exp } 14 b-(L): R^{\prime}=X=I, R^{\prime \prime}=M e, R=m \text {-xylyl, } L=\text { tmeda, pyridine, } P(P h)_{3}
\end{aligned}
$$

Figure 11. Structures of Grubbs-type complexes used in protonolysis studies.

Scheme 2. Protonolysis of Grubbs-Type Complexes in $\mathrm{CD}_{3} \mathrm{OD} /$ Benzene- $d_{6}$ Mixtures Observed by ${ }^{1} \mathrm{H}$ NMR Experiments

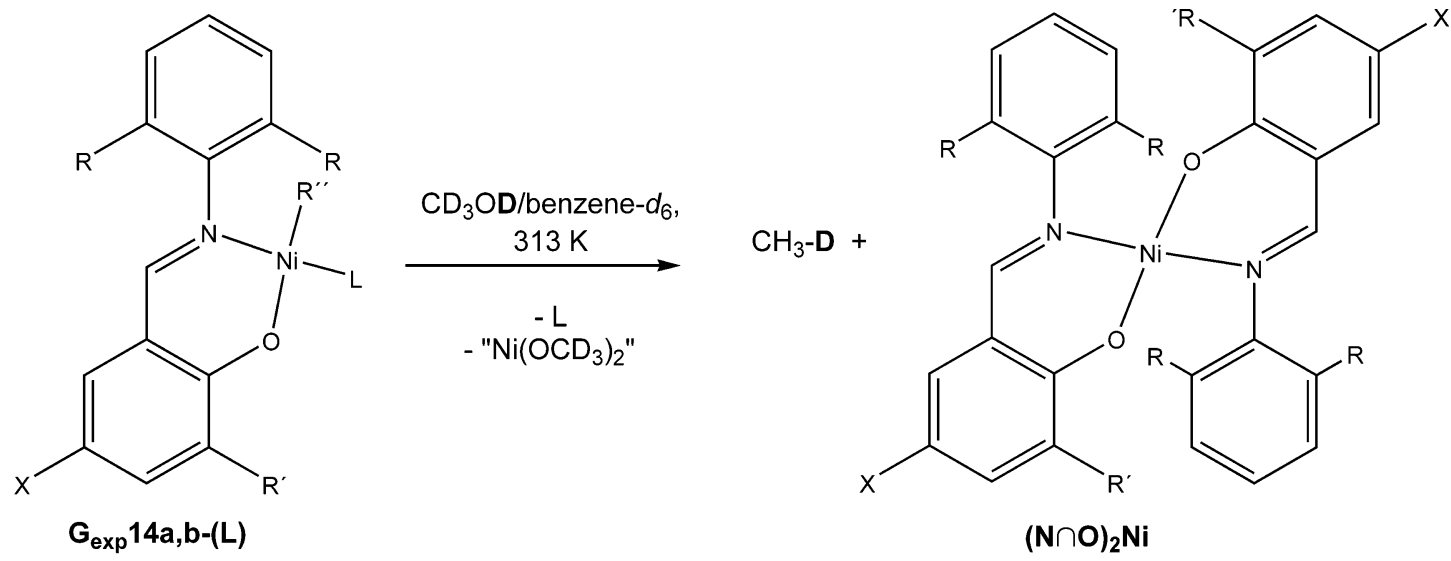

$$
\begin{aligned}
& \mathbf{G}_{\exp } \mathbf{1 4 a}-(\mathrm{L}): \mathrm{R}^{\prime}=X=I, R^{\prime \prime}=M e, R=3,5 \text {-bis(trifluoromethyl)phenyl, } L=\text { tmeda, pyridine, } P(P h)_{3} \\
& \mathbf{G}_{\exp } 14 b-(L): R^{\prime}=X=I, R^{\prime \prime}=M e, R=m \text {-xylyl, } L=\text { tmeda, pyridine, } P(P h)_{3}
\end{aligned}
$$

The half-life time $\left(t_{1 / 2}\right)$ of the reaction is ca. 23 min for complex $\mathbf{G}_{\mathbf{e x p}} \mathbf{1 4 a - ( t m e d a ) ~ a n d ~} 18 \mathrm{~min}$ for complex $\mathbf{G}_{\mathbf{e x p}} \mathbf{1 4 b}$ (tmeda) at $313 \mathrm{~K}$. Substitution of $\mathrm{L}=$ tmeda in complexes $\mathbf{G}_{\text {exp }}$ 14a,b-(L) by pyridine or $\mathrm{PPh}_{3}$ results in improved stability toward protonolysis with $t_{1 / 2}=$ ca. $6 \mathrm{~h}\left[\mathbf{G}_{\mathbf{e x p}} \mathbf{1 4 a}-\right.$ (pyridine)], ca. $4 \mathrm{~h}\left[\mathbf{G}_{\exp } \mathbf{1 4 b}\right.$-(pyridine)], and $\gg 5 \mathrm{~d}$ $\left[\mathbf{G}_{\exp } \mathbf{1 4 a}, \mathbf{b}-\left(\mathbf{P P h}_{3}\right)\right]$ under identical reaction conditions. Other than with complexes $\mathbf{G}_{\exp } \mathbf{1 4 a}, \mathbf{b}-(\mathbf{t m e d a})$, the respective pyridine or $\mathrm{PPh}_{3}$ complexes $\mathbf{G}_{\mathbf{e x p}} \mathbf{1 4 a}, \mathbf{b}$-(pyridine/PPh $\left.\mathbf{3}\right)$ are the only observed ground states of $\mathrm{Ni}-\mathrm{Me}$-containing species in these reaction mixtures. As for hydrolysis, addition of 10 vol $\%$ of deuterated water, e.g., to benzene- $d_{6} / \mathrm{CD}_{3} \mathrm{OD}$ solutions of $\mathbf{G}_{\mathbf{e x p}} \mathbf{1 4 a}, \mathbf{b}$-(tmeda), did not influence the reaction rates substantially. The increasing stability of complexes $\mathbf{G}_{\mathbf{e x p}} \mathbf{1 4 a , b - ( L )}$ toward protonolysis on going from $\mathrm{L}=$ tmeda to $\mathrm{PPh}_{3}$ mirrors the expected stabilization of the coordinatively unsaturated $(\mathrm{N} \cap \mathrm{O}) \mathrm{Ni}-\mathrm{Me}$ fragments by L. Likewise, we assume that this stabilization is higher for the more electron-deficient $\mathrm{Ni}$ center in complexes $\mathbf{G}_{\mathbf{e x p}} \mathbf{1 4 a -}(\mathbf{L})$ when compared to $\left.\mathbf{G}_{\mathbf{e x p}} \mathbf{1 4 b - (} \mathbf{L}\right)$. NMR assignments are given in the Supporting Information.
The aforementioned theoretical studies indicate that protonolysis is likely to occur, but will not be an extremely fast reaction. Also, comparison of the calculated insertion barrier from previous theoretical studies on salicylaldiminato complexes with the calculated barrier to hydrolysis indicated that protonolysis is likely to occur in polymerization experiments, but will not outrun polymerization entirely as chain growth is sufficiently rapid. In this sense, the preliminary experimental data is in good agreement with the theoretical results.

Since the barrier for the in-the-plane water attack was smaller than the barrier for the external water attack, at least for the generic Grubbs system, we decided to investigate only the former mechanism for the other structures. The substitution of the methyl ligand for phenyl (Figure 9c) leads to an increase in the barrier of hydrolysis by about $2 \mathrm{kcal}$ $\mathrm{mol}^{-1}$, which is due to the stronger M-phenyl bond and the steric repulsion accompanying the formation of benzene. Here we also looked at the hydrolysis of the $\mathbf{G 1 2}$ complex (Figure 9d) which exhibited the highest selectivity toward ethylene binding from all Ni-based Grubbs complexes. The barrier increased marginally, which is probably due to a 
a)

$\Delta \mathrm{E}(\mathrm{kcal} / \mathrm{mol})$

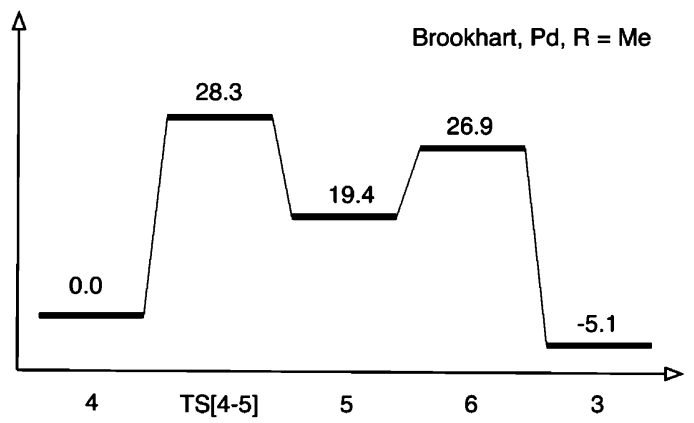

c)

$\Delta \mathrm{E}(\mathrm{kcal} / \mathrm{mol})$

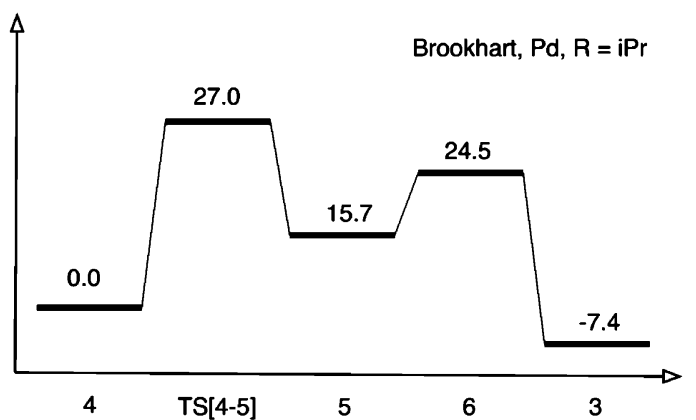

b)

$\Delta \mathrm{E}(\mathrm{kcal} / \mathrm{mol})$

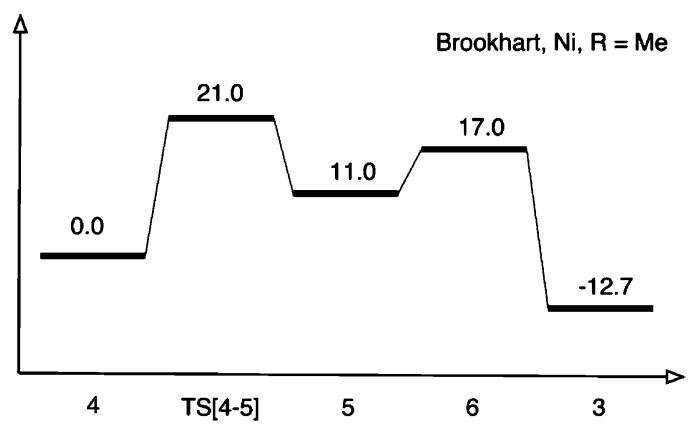

d)

$\Delta E(\mathrm{kcal} / \mathrm{mol})$

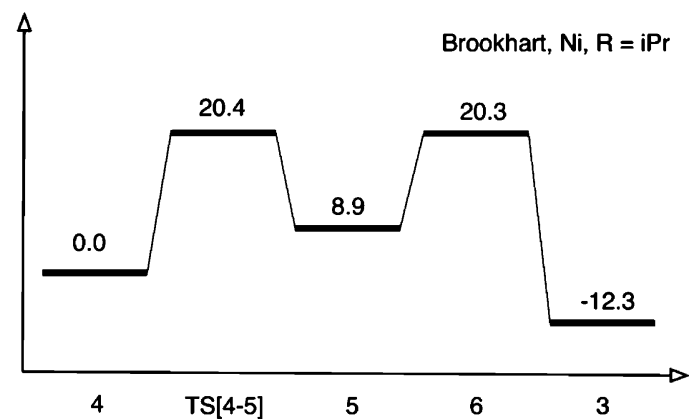

Figure 12. Energy diagram for the hydrolysis of the Brookhart catalysts. Energies in $\mathrm{kcal} \mathrm{mol}^{-1}$ in toluene.

C

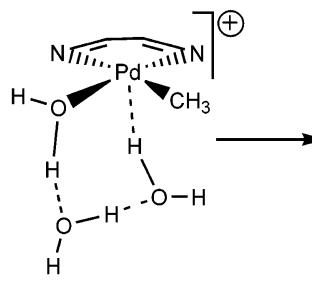

7

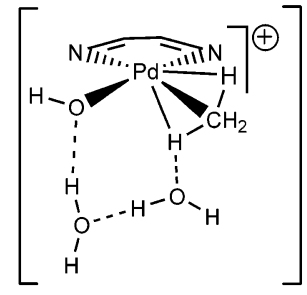

TS[7-8]

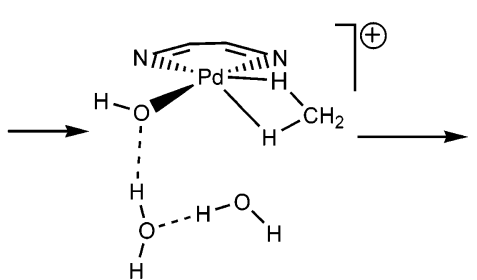

8

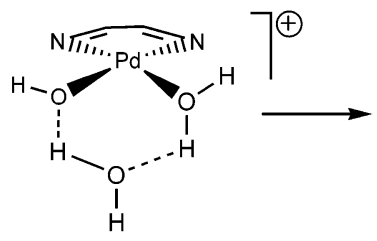

9

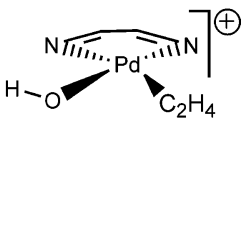

3

Figure 13. Solvent-assisted hydrolysis mechanism for the Brookhart system, internal water attack.

further increase in the M-phenyl bond strength as the 2,6${ }^{i}$ Pr groups increase the back-donation ability of the metal. The steric requirements for the reaction make it impossible for a product complex of benzene ( 5 in Figure $6 \mathrm{~b}$ ) to be observed.

The highest barrier of $21.7 \mathrm{kcal} \mathrm{mol}^{-1}$ was obtained for the Pd-based system (G13), Figure 9b. A similar hydrolysis process has been observed before for the formic acid hydrolysis of a $\mathrm{Pd}(\mathrm{II})-\mathrm{CH}_{3}$ complex where the barrier was $28.5 \mathrm{kcal} \mathrm{mol}^{-1} .^{35}$ The results suggest that the Pd-based Grubbs catalyst that was shown to have the highest preference for ethylene complexation will also have a high hydrolysis barrier, making it the most stable species toward water of all Grubbs systems studied here. It must be noted, however, that experimental studies with other neutral palladium complexes to date have found them to be rather sluggish polymerization catalysts. ${ }^{36}$

Brookhart Catalyst Hydrolysis. For the Brookhart system we again considered only the water attack in the plane of

(35) Biswas, B.; Sugimoto, M.; Sakaki, S. Organometallics 2000, 19, 3895. the complex. The energy diagrams for the Brookhart systems are shown in Figure 12.

Here the effect of the substituent R group is small-the introduction of the electron donating ${ }^{\mathrm{P}} \mathrm{Pr}$ groups in place of $\mathrm{R}=$ Me results in more stable hydroxo complexes 5 but the barrier in TS[4-5] is virtually unaffected. The change in the metal has a stronger influence. The highest barrier is exhibited by the Pd-based systems (Figure 12a,c) since they are less oxophilic compared to the Ni-based systems. The complex shown in Figure 12a (B1) has the highest barrier of hydrolysis out of all studied compounds. For this reason a slight modification to the hydrolysis mechanism, involving the inclusion of an additional two solvent water molecules in the active site, shown in Figure 13, was studied for this particular complex. It was reported by Siegbahn ${ }^{13}$ that water chains significantly lower the calculated barriers for the

(36) (a) Britovsek, G. J. P.; Keim, W.; Mecking, S.; Sainz, D.; Wagner, T.; Hemilabile P, O-Ligands in Palladium Catalysed C-C Linkages, J. Chem. Soc., Chem. Commun. 1993, 1632. (b) Drent, E.; van Dijk, R.; van Ginkel, R.; van Oort, B.; Pugh, R. I. Chem. Commun. 2002, 964. 


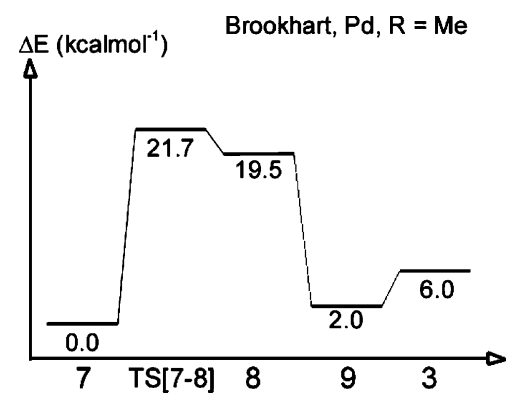

Figure 14. Energy diagram for the solvent-assisted hydrolysis of the $\mathrm{Pd}$ Brookhart catalyst where $\mathrm{R}=\mathrm{Me}$. Energies in $\mathrm{kcal} \mathrm{mol}^{-1}$ in toluene.

Wacker process, and we wished to ascertain whether using a water chain model would have a similar effect on barrier for the Brookhart system.

In this mechanism two water molecules bind to $\mathbf{4}$ to give a three water molecule chain bound to the complex, with the tail hydrogen atom of the chain being weakly bound to the $\mathrm{Pd} \mathrm{dz}^{2}$ orbital, to give complex 7. This step is exothermic by $11.1 \mathrm{kcal} \mathrm{mol}^{-1}$. The first water molecule then provides the hydroxyl group to the metal, and the third water molecule provides the proton to the methyl group, with the central water molecule providing the bridge for the "Proton Shuttle" ${ }^{37-43}$ transfer of the proton. The methyl group is thus hydrolyzed to give the agostic methane-bound structure $\mathbf{8}$, which then evolves methane to give structure 9 with the tail end of the water chain bound to the palladium coordination site vacated by the methane ligand. Two water molecules are then lost back to solvent as an ethene molecule binds to the palladium to give structure 3 .

The energy diagram for this process is shown in Figure 14.

The transition state for the hydrolysis, shown in Figure 15 , is distinctly product-like, as would be expected from an endothermic process, with the two additional water molecules sited at long hydrogen bonding distances from the hydroxyl and (nearly fully formed) agostically bound methane ligand.

This solvent-assisted mechanism lowers the energy of the hydrolysis transition state to $21.7 \mathrm{kcal} \mathrm{mol}^{-1}, 6.6 \mathrm{kcal} \mathrm{mol}^{-1}$ lower than the barrier found without the solvent assistance, whereas the endothermicity of the reaction remains the same at $19.4 \mathrm{kcal} \mathrm{mol}^{-1}$. Loss of the methane molecule to give the hydroxyl/water chain ligated complex $\mathbf{9}$ is exothermic by $17.2 \mathrm{kcal} \mathrm{mol}^{-1}$, giving a structure only $2.0 \mathrm{kcal} \mathrm{mol}^{-1}$ higher in energy than 7. Displacement of the two water molecules by an ethene molecule to give $\mathbf{3}$ is endothermic by a further $4.0 \mathrm{kcal} \mathrm{mol}^{-1}$, making the total process endothermic by $6.0 \mathrm{kcal} \mathrm{mol}^{-1}$. Although it has been shown (Table 2, compound B1) that the preference for ethene binding over water binding is $6.3 \mathrm{kcal} \mathrm{mol}^{-1}$, this energetic

(37) Olsen, L.; Antony, J.; Ryde, U.; Adolph, H. W.; Hemmingsen, L. J. Phys. Chem. B 2003, 107, 2366.

(38) Tu, C. K.; Rowlett, R. S.; Tripp, B. C.; Ferry, J. G.; Silverman, D. N. Biochemistry 2002, 41, 15429.

(39) Rao, B. G.; Singh, U. C. J. Am. Chem. Soc. 1991, 113, 6735.

(40) Cummins, P. L.; Gready, J. E. J. Am. Chem. Soc. 2001, 123, 3418.

(41) Tse, J. S. Anпи. Rev. Phys. Chem. 2002, 53, 249.

(42) Lee, S. H. Bull. Korean Chem. Soc. 2001, 22, 847.

(43) Marx, D.; Tuckerman, M. E.; Hutter, J.; Parrinello, J. Nature 1999 397, 601 .

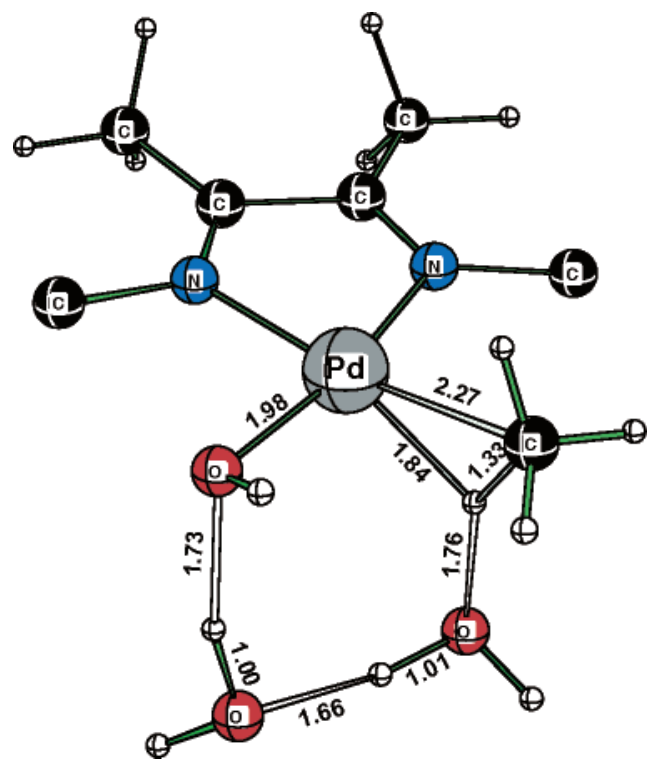

Figure 15. Transition state structure for the solvent-assisted internal hydrolysis of the Pd Brookhart catalyst B1.

preference is not large enough to compensate for the loss of the hydrogen bond in the chain, coupled with the greater nucleophilicity of the water molecule when one of its hydrogen atoms is involved in hydrogen bonding, leading to a stronger palladium-oxygen interaction.

However, the entropic cost of binding the additional two water molecules must be taken into account when considering whether this solvent-assisted mechanism provides a better model than the unassisted pathway. Literature figures give the entropic penalties for ligand binding to a square planar complex between 9 and $17.2 \mathrm{kcal} \mathrm{mol}^{-1}$, dependent on the system. ${ }^{44-48}$ This entropic penalty eclipses the energetic advantage of the solvent-assisted mechanism, making it an unlikely pathway.

O-P Catalyst Hydrolysis. The energy diagram for the $\mathrm{O}-\mathrm{P}$ chelate system is shown in Figure 16.

Here the Ni compounds (Figure 16b,d) exhibit the same trend as the neutral Grubbs system, while the profiles for the Pd compounds (Figure 16a,c) are like the ones observed in the Brookhart complexes. This difference can be explained by examining the charges on the metal centers in the two cases. The positive charge on $\mathrm{Ni}$ in the $\mathrm{O}-\mathrm{P}$ chelate system is very small (0.303), while for Pd it is 0.613 . Thus, the $\mathrm{Pd}$ system will have the features of the cationic Brookhart system, while the Ni system will have features which are closer to the neutral Grubbs system.

\section{Conclusions}

All three catalyst systems investigated here (Figure 1) show similar trends with regard to the preference of binding

(44) Mecking, S.; Johnson, L. K.; Wang, L.; Brookhart, M. J. Am. Chem. Soc. 1998, 120, 888.

(45) Michalak, A.; Ziegler, T. Organometallics 2003, 22, 2069.

(46) Moullet, B.; Zwahlen, C.; Frey, U.; Gervasio, G.; Merbach, A. E. Inorg. Chim. Acta 1997, 261, 67.

(47) Hallinan, N.; Besancon, V.; Forster, M.; Elbaze, G.; Ducommun, Y.; Merbach, A. E. Inorg. Chem. 1991, 30, 1112.

(48) Helm, L.; Elding, L. I.; Merbach, A. E. Helv. Chim. Acta 1984, 67 1453. 
a) O-P chelate, $\mathrm{Pd}-\mathrm{Ph}$

$\Delta \mathrm{E}(\mathrm{kcal} / \mathrm{mol})$

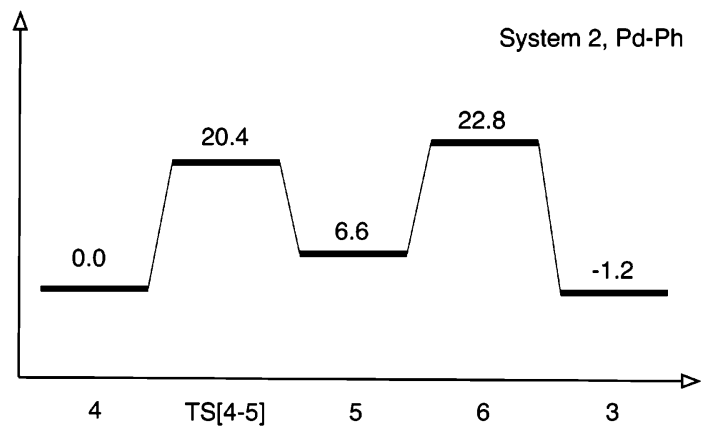

c) O-P chelate, Pd-Me $\Delta \mathrm{E}(\mathrm{kcal} / \mathrm{mol})$

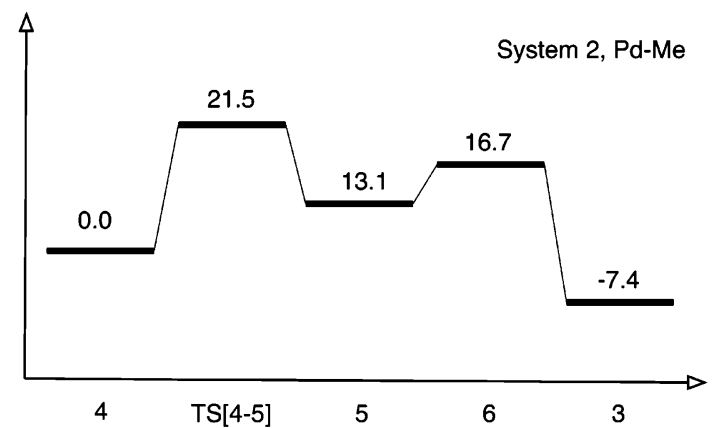

b) $\mathrm{O}-\mathrm{P}$ chelate, $\mathrm{Ni}-\mathrm{Ph}$

$\Delta \mathrm{E}(\mathrm{kcal} / \mathrm{mol})$

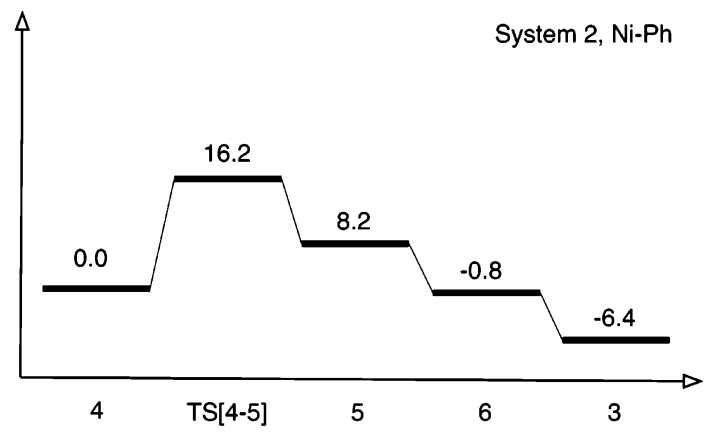

d) O-P chelate, $\mathrm{Ni}-\mathrm{Me}$ $\Delta \mathrm{E}(\mathrm{kcal} / \mathrm{mol})$

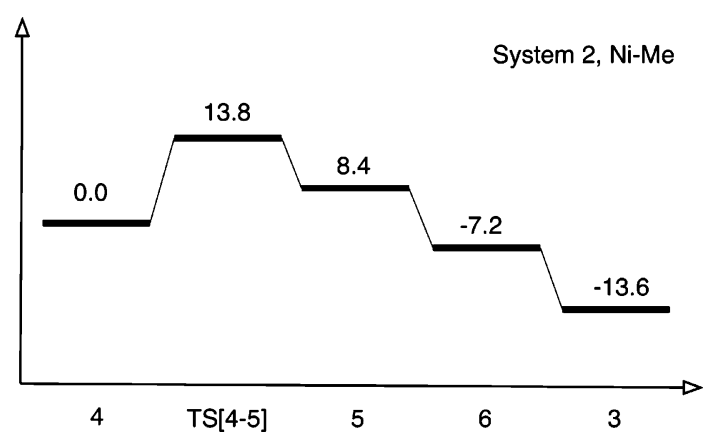

Figure 16. Energy diagram for the hydrolysis of the $\mathrm{O}-\mathrm{P}$ chelate catalysts. Energies in $\mathrm{kcal}^{\mathrm{mol}} \mathrm{l}^{-1}$ in toluene.

ethene over water, with the greatest preference for ethene found for palladium rather than nickel. This is understandable since the more diffuse d-orbitals have better bonding $\pi$-overlaps with the olefin. At the same time, the more diffuse occupied orbitals of palladium interact more repulsively with the occupied oxygen lone pairs, leading to a weaker binding of water. The nature of the substituent groups was also important in that more electron-donating substituents lead to a greater preference for ethene over water, though these effects did not appear to be directly cumulative in that multiple substitutions did not give rise to significantly higher preference than single ligand substitutions. The catalyst with the greatest preference for ethene over water was the Grubbs catalyst G13, with Pd and unsubstituted ligands.

Hydrolysis of the three catalyst systems (Figure 1) proceeded in a similar manner-substitution of the ethene ligand with water proved to be a more favorable approach than axial attack of water on the palladium center. The structures that showed greater preference for ethene binding over water also had higher barriers to hydrolysis, with the Brookhart catalysts showing the greatest resistance to hy- drolysis. While solvent assistance in the hydrolysis lowered the energetic barrier, it was not sufficient to offset the entropic penalty of binding additional water molecules. It is found that in general that (a) ethylene coordination is preferred over water coordination for both $\mathrm{Ni}$ and $\mathrm{Pd}$ catalysts and (b) hydrolysis of the metal alkyl bond is competitive to ethylene insertion.

Acknowledgment. This work has been supported by the National Sciences and Engineering Research Council of Canada (NSERC). R.D.K. wishes to acknowledge the donors of the American Chemical Society Petroleum Research Fund for partial support of this work. T.Z. thanks the Canadian Government for a Canada Research Chair. G-S. and S.M. thank the DFG for financial support (AM2Net: Me 13883).

Supporting Information Available: Individual NMR assignments for the experimental investigations into hydrolysis of the Grubbs catalyst. This material is available free of charge via the Internet at http://pubs.acs.org. 